\title{
OBEDIS Core Variables Project: European Expert Guidelines on a Minimal Core Set of Variables to Include in Randomized, Controlled Clinical Trials of Obesity Interventions
}

\author{
Maud Alligier ${ }^{a}$ Romain Barrès ${ }^{b} \quad$ Ellen E. Blaak ${ }^{c}$ Yves Boirie $^{d} \quad J_{i l d a u} B$ Bouwman ${ }^{e}$ \\ Paul Brunault ${ }^{f} \quad$ Kristina Campbellg Karine Clément ${ }^{h} \quad$ I. Sadaf Farooqi ${ }^{i}$ \\ Nathalie J. Farpour-Lambert ${ }^{j}$ Gema Frühbeckk Gijs H. Goossens' Jorg Hager ${ }^{m}$ \\ Jason C.G. Halford ${ }^{n}$ Hans Hauner ${ }^{\circ}$ David Jacobi ${ }^{p}$ Chantal Julia ${ }^{q}$ Dominique Langin ${ }^{r}$

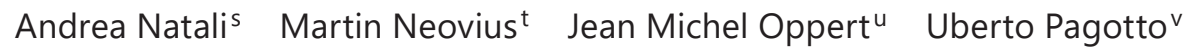 \\ Antonio L. Palmeiraw Helen Roche ${ }^{x}$ Mikael Rydén ${ }^{y}$ André J. Scheen ${ }^{z}$ Chantal Simon ${ }^{A}$ \\ Thorkild I.A. Sorensen ${ }^{B}$ Luc Tappy ${ }^{C}$ Hannele Yki-Järvinen ${ }^{D}$ Olivier Ziegler ${ }^{E}$ \\ Martine Laville ${ }^{\mathrm{F}}$
}

aFCRIN/FORCE Network, Centre de Recherche en Nutrition Humaine Rhône-Alpes, Lyon, France; ${ }^{b}$ Novo Nordisk Foundation Center for Basic Metabolic Research, Faculty of Health and Medical Sciences, University of Copenhagen, Copenhagen, Denmark; ' ${ }^{\mathrm{D}}$ epartment of Human Biology, Maastricht University Medical Centre+, Maastricht, The Netherlands; ${ }^{d}$ University Clermont Auvergne, CHU Clermont-Ferrand, Clinical Nutrition Department, Unité de Nutrition Humaine, CRNH Auvergne, Clermont-Ferrand, France; eTNO (Netherlands Organization for Applied Scientific

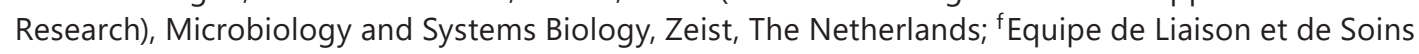
en Addictologie, CHRU de Tours, and UMR 1253, iBrain, Université de Tours, Inserm, and Qualipsy EE 1901, Université de Tours, Tours, France; ${ }^{9}$ KC Microbiome Communications Group, Victoria, BC, Canada; ${ }^{h}$ Sorbonne University/INSERM, Nutrition and Obesities, Systemic Approaches Research Unit, and Assistance Publique Hôpitaux de Paris, Nutrition Department, Pitié-Salpêtrière Hospital, Paris, France; 'Wellcome-MRC Institute of Metabolic Science and NIHR Biomedical Research Centre, University of Cambridge, Cambridge, UK; jObesity Prevention and Care Program Contrepoids, Service of Therapeutic Education for Chronic Diseases, Department of Community Health, Primary Care and Emergency, Geneva University Hospitals and University of Geneva, Geneva, Switzerland; kDepartment of Endocrinology and Nutrition, Clínica Universidad de Navarra, University of Navarra \& CIBEROBN, IdiSNA, Pamplona, Spain; 'Department of Human Biology, NUTRIM School of Nutrition and Translational Research in Metabolism, Maastricht University Medical Centre+, Maastricht, The Netherlands; ${ }^{m}$ Metabolic Phenotyping, Nestlé Institute of Health Sciences, Lausanne, Switzerland; nPsychological Sciences, University of Liverpool, Liverpool, UK; ${ }^{\circ}$ Institute of Nutritional Medicine, Klinikum rechts der Isar, Technical University of Munich, Munich, Germany; ${ }^{\mathrm{P} L ' I n s t i t u t ~ d u ~ T h o r a x, ~}$ INSERM, CNRS, UNIV Nantes, CHU Nantes, Nantes, France; ' Nutritional Epidemiology Research Team (EREN), Epidemiology and Statistics Research Center (CRESS), Inra, Cnam, Paris 13 University and Public Health Department, Avicenne Hospital, AP-HP, Bobigny, France; 'Institute of Metabolic and Cardiovascular Diseases, I2MC, Inserm, Paul Sabatier University, and Department of Medical Biochemistry, Toulouse University Hospitals, Toulouse, France; ${ }^{s}$ Department of Clinical and Experimental Medicine, University of Pisa, Pisa, Italy; ${ }^{\mathrm{t} D e p a r t m e n t ~ o f ~ M e d i c i n e ~(S o l n a), ~ K a r o l i n s k a ~}$ Institute, Stockholm, Sweden; "Department of Nutrition, Pitié-Salpêtrière Hospital (AP-HP), Sorbonne 
Alligier et al.: OBEDIS Core Variables Project

University, Institute of Cardiometabolism and Nutrition (ICAN), Paris, France; ${ }^{2}$ Department of Medical and Surgical Sciences, Alma Mater Studiorum University of Bologna, Policlinic S. Orsola,

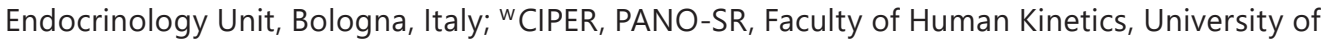
Lisbon, Lisbon, Portugal; ${ }^{x}$ Nutrigenomics Research Group, UCD Institute of Food \& Health, University College Dublin, Dublin, Ireland; y Department of Medicine (H7), Karolinska Institutet, Karolinska University Hospital, Stockholm, Sweden; 'Liège University, Division of Diabetes, Nutrition and Metabolic Disorders, CHU Liège, Liège, Belgium; ACarMen Laboratory, INSERM 1060, INRA 1397, University of Lyon, Oullins, France; ${ }^{B}$ Novo Nordisk Foundation Center for Basic Metabolic Research, and Department of Public Health, Faculty of Health and Medical Sciences, University of Copenhagen, Copenhagen, Denmark; ${ }^{C}$ Physiology Department, Faculty of Biology and Medicine, University of Lausanne, Lausanne, Switzerland; D University of Helsinki, Helsinki University Hospital, and Minerva Foundation Institute for Medical Research, Helsinki, Finland; EDepartment of Endocrinology, Diabetes and Nutrition, Hôpital Brabois Adultes, CHRU de Nancy, Vandoeuvre Lès Nancy, France; FFCRIN/ FORCE Network, Centre de Recherche en Nutrition Humaine Rhône-Alpes, Université de Lyon, Hospices Civils de Lyon, Lyon, France

\title{
Keywords
}

Obesity $\cdot$ Interventions $\cdot$ Variables $\cdot$ Precision medicine $\cdot$ Stratification

\begin{abstract}
Heterogeneity of interindividual and intraindividual responses to interventions is often observed in randomized, controlled trials for obesity. To address the global epidemic of obesity and move toward more personalized treatment regimens, the global research community must come together to identify factors that may drive these heterogeneous responses to interventions. This project, called OBEDIS (OBEsity Diverse Interventions Sharing - focusing on dietary and other interventions), provides a set of European guidelines for a minimal set of variables to include in future clinical trials on obesity, regardless of the specific endpoints. Broad adoption of these guidelines will enable researchers to harmonize and merge data from multiple intervention studies, allowing stratification of patients according to precise phenotyping criteria which are measured using standardized methods. In this way, studies across Europe may be pooled for better prediction of individuals' responses to an intervention for obesity - ultimately leading to better patient care and improved obesity outcomes.
\end{abstract}

\section{Introduction}

Obesity is a problem that represents a significant health and economic burden in Europe and throughout the world. The prevalence of obesity across European countries has tripled in the last several decades [1], making it one of the leading public health challenges.

A critical part of addressing this global epidemic is to improve the evidence base for more effective treatments for obesity; however, a challenge revealed in the randomized, controlled trials (RCTs) of obesity interventions is the remarkable heterogeneity of interindividual and intraindividual responses among adult patients - whether the intervention pertains to lifestyle (dietary, physical activity [PA]), or is a pharmacological or surgical intervention aiming at weight loss. Most obesity RCTs include a heterogeneous mixture of patients that, despite meeting the inclusion criteria for the study, vary remarkably when it comes to the medical 
history of their disease, associated complications, and many other factors (including genetics, lifestyle, environmental, and psychosocial factors) that may drive the varying responses to the same intervention. Also, different trials take different approaches to measuring the same variable. This emphasizes the need to appropriately stratify patients according to precise phenotyping criteria, as measured using standardized methods, that might predict an individual's response to an intervention: enabling a paradigm shift in individually tailored obesity treatment, going from "one-size-fits-all" to precision medicine.

One important clinically relevant question is whether, among the patients who respond poorly to a given therapy, a better response might be achieved by applying a different therapy or by administering the current therapy differently. Specific patient characteristics could theoretically provide justification for choosing an alternative treatment either as a first choice or, dependent on poor response, as a second choice, but an increased burden is thus placed on researchers to provide evidence for the benefit of choosing or switching between alternative therapies.

Even for the largest and most comprehensive published clinical studies on obesity, stratification leads to subgroup analyses with reduced statistical power. Moreover, some trials do not report methods for measuring relevant obesity phenotypes in sufficient detail. Thus, it is necessary to harmonize and merge the data from multiple intervention studies - but data pooling is only possible with trials that include a common set of variables measured in the same way, including samples that are collected using consistent methods or procedures, described in enough detail.

Funded by a European grant, a group of European obesity researchers convened in 2018 to create a plan for helping shape future RCTs in the field of obesity by identifying the minimal set of variables that should be included in trials of different kinds of obesity interventions, whatever the type and the endpoints of the intervention. The experts intend for this minimal core set to be adopted in future studies while acknowledging that in addition, RCTs or other trials will collect data on extra variables, depending on the specific area of focus. As such, the current initiative, called OBEDIS (OBEsity Diverse Interventions Sharing - focusing on dietary and other interventions) and funded by the Joint Programming Initiative - A Healthy Diet for a Healthy Life (JPI HDHL), was created to provide the research community with a blueprint for designing future RCTs in order to allow the sharing and merging of datasets, and to enable meaningful subgroup analyses. To achieve this, the OBEDIS experts surveyed the scientific literature, especially the published work on stratifying populations of individuals with obesity. They shared their expert opinions on a recommended minimal core set of variables to be included in all future trials of adult obesity interventions and sought to reach consensus on both these variables and the related assessment methods.

\section{Methods}

\section{Expert Involvement and Working Methods}

The OBEDIS project coordinators, supported by the European Association for the Study of Obesity (EASO), invited leading experts to contribute to this consensus on a minimal core set of variables for RCTs of obesity interventions. These European researchers represented 13 countries and were chosen for their research record and expertise related to obesity and intervention studies in the field. The total group was comprised of 30 experts (including the 4-person coordination/management team); three scientific advisory board (SAB) members; one project manager; one funding agency (JPI HDHL) representative; and one medical writer. The OBEDIS experts were purposely selected from countries with different healthcare models and demographics. These multiple perspectives were considered necessary in the discus- 
Alligier et al.: OBEDIS Core Variables Project

sions, in order to serve the field best by choosing a minimal core set of variables that are applicable across different geographies and cultures.

The experts were divided into small working groups according to their expertise. They completed reviews of published RCTs in their respective domains and held initial discussions. After this foundational preparatory group work, these experts and SAB members met for a 2-day workshop in Paris, France, in October 2018, to discuss the recommendations and come to a consensus on a core set of variables to recommend in each domain.

\section{Criteria for Minimal Core Set}

A variable is defined as "a property with respect to which individuals in a sample differ in some ascertainable way" [2]. The minimal core set is a set of variables recommended to be measured in all trials for obesity, regardless of the type of intervention. It is understood that over time this core set will be updated according to the scientific advances in each of the identified domains.

For a variable to be included in the minimal core set, it was required to fulfill the following criteria:

- It provided information that made it likely to impact treatment response, according to the relevant literature (especially studies that aimed to stratify patients)

- It was feasible: Given that each clinical trial has limits on budget and time as well as research team expertise, the OBEDIS group aimed to minimize the burden of including each variable in future trials. The scientists paid considerable attention to factors that would encourage widespread adoption of these measures by the European obesity research community, especially the overall number of variables that should be systematically collected. The group preferred measures that were:

- Low-cost or free to utilize/able to be collected with minimal equipment or human resources

- Less invasive/quick to implement

- For questionnaires: Available and/or validated in multiple languages or across cultures The group provided an estimate of the average cost of including these measures in a European trial (Table 1). While inclusion of these variables will in some cases introduce additional cost to individual clinical trials, they will also extend the insights made possible by each trial - making the overall research agenda proceed more purposefully and at a lower cost.

While the primary purpose of the initiative was to identify a minimal core set, additional relevant variables and/or measures were identified in some cases, and these were included in what was called the "expanded set."

\section{Selection of Minimal Core Set}

Each group presented the variables frequently used in the studies to date, and selected them based on their experience, the scientific literature, and their projections about the future direction of the field in each domain. The group then voted on each item in the minimal core set (with the outcome determined by a simple majority). The approach to this OBEDIS project was pragmatic and guided at every turn by the existing body of evidence on interventions for obesity while taking into account the constraints of the minimal core set.

The experts understand that few trials will restrict themselves to only this core set and will collect additional variables depending on their specific aims and outcomes. Trial investigators may opt to carry out more detailed measurements for a certain variable when it corresponds to the main objective of the study - and in this case, regardless, the OBEDIS group recommends collecting the overlapping measures in the minimal core set to facilitate data integration on a larger scale. 

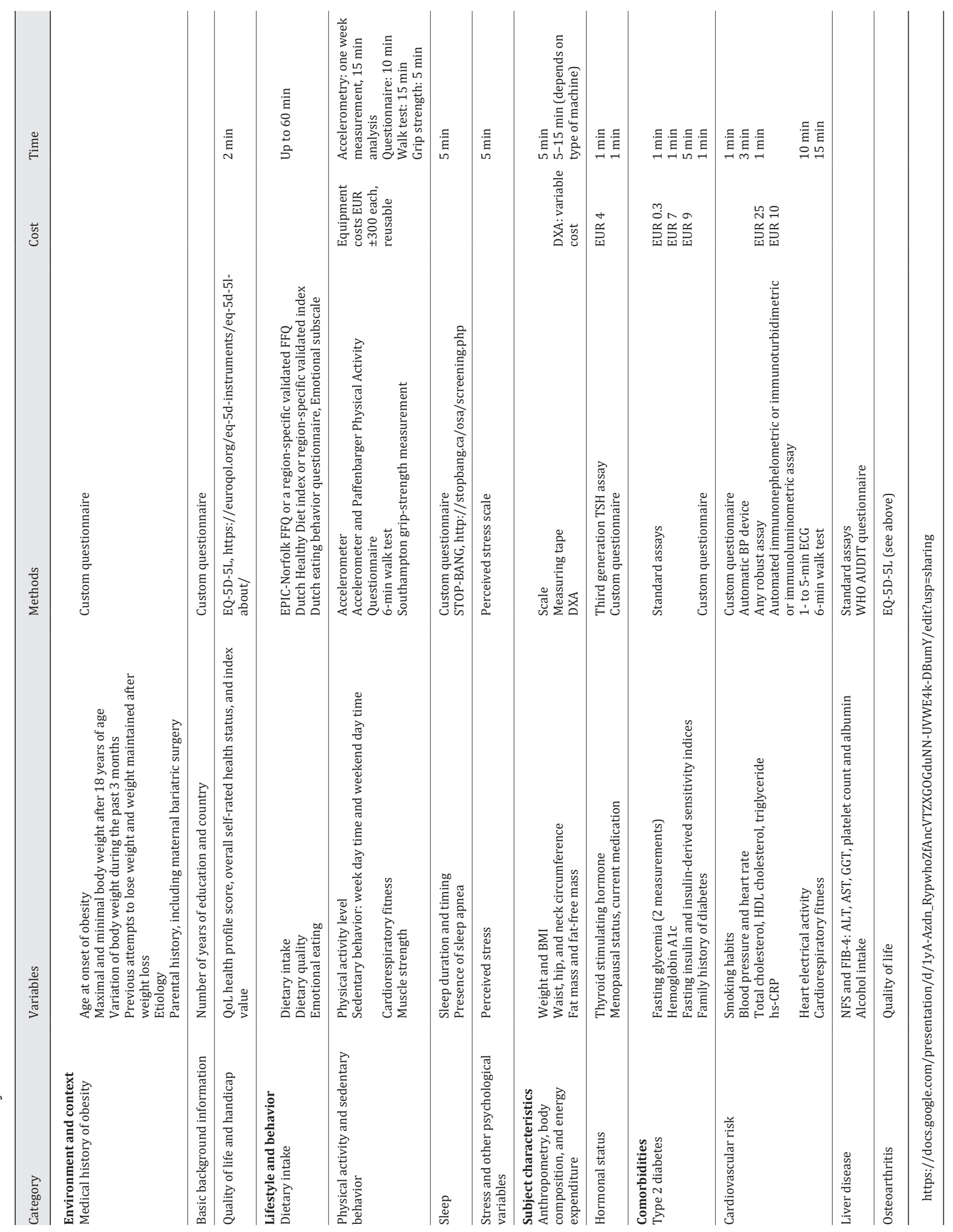
Alligier et al.: OBEDIS Core Variables Project

\section{Parallel Efforts}

The OBEDIS work with European experts occurred in parallel with a similar United States initiative funded by the National Institutes of Health: the ADOPT (Accumulating Data to Optimally Predict obesity Treatment) core measures project [3]. In the OBEDIS workshop, the experts noted that the existence of this parallel work highlights the need for such efforts in the field. OBEDIS scientists wish to connect ideas across these two projects and build joint efforts in the same direction, for the overall benefit of the field globally.

\section{Results}

The expert guidelines detailed herein represent a practical advancement in the field of research on obesity interventions. Below, the results are described in four categories - environment and context, lifestyle, subject characteristics, and complications - with a final section looking ahead to implications for future medical practice. Table 1 summarizes the variables and methods. Issues pertaining to obesity interventions are covered in a separate paper.

The OBEDIS experts unanimously agreed that standard operating procedures (SOPs) are of critical importance, because only with consistent harmonized procedures can data be pooled across studies. The recommended detailed assessment methods for these measurements are detailed in the supplementary materials (for all online suppl. materials, see www. karger.com/doi/10.1159/000505342).

Environment and Context: Medical History of Obesity, Basic Background Information, Quality of Life/Handicap

No living entity exists in isolation: across the biological sciences, researchers consider environmental influences as major drivers of behavioral change. Various environmental factors are considered relevant in obesity, since they may contribute to the emergence and maintenance of the condition and relevant behaviors. The context where patients live and work may also impact response to interventions, making contextual factors potentially useful for patient stratification at baseline.

Medical History of Obesity

Minimal core set recommended variables:

- Age at onset of obesity

- Maximal and minimal body weight after 18 years of age

- Variation of body weight during the past 3 months

- Previous attempts to lose weight and weight maintained after weight loss

- Etiology: categories from Hebebrand et al. [4]

- Parental history, including history of bariatric surgery

Expanded set recommended variables:

- Body weight self-monitoring

The medical history of obesity is a recall of weight-related events and problems experienced by the patient. In adult obesity, the medical history of the disease is important because factors in the history of a patient can not only affect the course of weight gain and loss through the lifespan but may modulate the response to a specific type of intervention. Medical history variables in three main categories are relevant to intervention responses: the development of the current obesity state and previous attempts to treat it; the disease etiology; and variables related to conception and perinatal history. Comorbid medical conditions that may influence intervention outcome, or disorders for which the treatment influences outcome, are discussed elsewhere in this paper. 
In considering the development of the patient's current obesity state, the OBEDIS group recommends documenting both the age of the onset of obesity, and the maximal and minimal body weight during adulthood. The age at obesity onset is important because occurrence prior to age 18 can influence the development of complications later on [5]. Meanwhile, minimal and maximal body weight in adulthood are also relevant; in particular, using maximum body mass index (BMI; rather than using BMI at the time of study) to assess mortality risks leads to stronger associations between excess weight and mortality [6]. Another potentially important factor is recent body weight fluctuations [7]; the group recommended assessing weight changes over the past 3 months. Assessing body weight self-monitoring behaviors is not recommended for the minimal core set of variables but may be included in the expanded set.

Previous attempts to treat obesity are also relevant: for instance, in some studies a greater number of previous weight loss attempts predicted greater weight loss [8] and some evidence suggests weight cycling may increase the likelihood of future weight gain [9]. Data for the minimal core set should include: the number of attempts, whether the patient has undertaken individual/group behavioral interventions (pertaining to nutrition/PA/psychology), whether treatment included obesity drugs or bariatric surgery, and the maximal weight loss and weight regain as a result of these attempts.

The etiology of the patient's obesity may affect response to intervention. In most individuals with obesity, the disease is multifactorial - that is, resulting from the complex interaction of many genetic/epigenetic and environmental factors. However, in cases where a defined etiological factor can be identified (a genetic mutation, for example), the OBEDIS group recommends using the categories outlined in Hebebrand et al. [4]. Trained medical staff should be able to identify syndromic obesity to either avoid the inclusion of these patients if the trial is not specific to genetic obesity or include these patients as a separate subgroup.

Factors related to periconceptional and perinatal history of the patient may also affect response to obesity interventions [10]: family disease history, maternal obesity before conception, complications and health conditions during pregnancy (including maternal gestational diabetes), magnitude of gestational weight gain, preterm or term birth, and birth weight (macrosomia). Typically, not all of this information is known to the patient, but in the minimal core set the OBEDIS group recommends assessing two particularly important factors prior to conception: parental obesity [11] and maternal history of bariatric surgery.

No standardized medical history questionnaire for obesity is in use throughout Europe. Various standardized questionnaires exist to assess some of the above items, but many are not available in different European languages. Thus, the OBEDIS group recommends assessing the above medical history variables via custom questionnaire (self-report), specified in the supplementary materials. Where available, medical records (registers or electronic medical charts) may be used to corroborate the information.

The group agrees that, in the future, researchers should set about developing a standardized clinical questionnaire related to the medical history of obesity, which would be translated into different languages for use by researchers and healthcare professionals across Europe. A further endeavor - which would prove extremely valuable for research purposes - is to develop a European register of health information that included data on medical history, health status, and treatment of individuals over time.

Basic Background Information

Minimal core set recommended variables:

- Number of years of education and country

Both education and other measures of socioeconomic status, such as income, may modify intervention outcomes for certain kinds of obesity interventions. Variations across education 
Alligier et al.: OBEDIS Core Variables Project

level were observed for the outcome suicide and self-harm when comparing a dietary/lifestyle modification program and bariatric surgery [12]; a similar pattern was found for the outcome of sleep medication use [13]. In higher-income countries, an inverse association tends to exist between educational attainment and obesity [14].

Number of years of education is widely used for assessing patient educational attainment [15] and is recommended in this context. While this measure does not allow complete comparability of data between countries, the minimal core dataset would ideally specify the country along with the number of years of education.

Quality of Life/Handicap

Minimal core set recommended variables:

- Quality of life (QoL): EQ-5D-5L health profile scores, overall self-rated health status, and index value

QoL is a subjective factor that is defined by the World Health Organization (WHO) as "an individual's perception of their position in life in the context of the culture and value systems in which they live and in relation to their goals, expectations, standards and concerns" [16]. Health-related QoL is a broad-ranging, multidimensional assessment of one's own health; it is an outcome measure that is frequently assessed along with handicap: "a disadvantage for a given individual that limits or prevents the fulfillment of a role that is normal for that individual" [17]. Given that health is "a state of complete physical, mental, and social well-being and not merely the absence of disease or infirmity" [18], a complete assessment of health status - especially in chronic diseases - should include both objective measures (using a biomedical framework) and subjective measures (using a psychosocial framework; e.g., QoL) $[19,20]$.

In the field of obesity research, health-related QoL can be an independent outcome variable for assessing the effectiveness of therapeutic strategies for obesity, complementary to the degree of weight loss and to the improvement in complications [21, 22]. In addition to its outcome value, QoL can also have predictive value (i.e., prediction of biopsychosocial outcomes) and discriminative value (e.g., differentiating between patients with or without other medical conditions) [23]. QoL is an important variable in economic evaluation of healthcare interventions, as it is used to calculate quality-adjusted life years, the most commonly used effect measure in cost-effectiveness analyses.

QoL, as a patient-reported outcome, is assessed using self-administered questionnaires. Many questionnaires have been validated in the field of obesity [for reviews see 24, 25]. The OBEDIS group used several criteria (consistent with the general criteria above) to choose the most suitable QoL questionnaire: type of concept assessed (i.e., assessment of QoL, but not symptoms/functional status or handicap), brevity, convergent validity, cross-cultural validation (particularly important in this European work), and copyright (including no or limited fees for use). The European group agrees that the EQ-5D-5L satisfies the greatest number of criteria for suitability of widespread use - especially cross-cultural validation, minimal number of items, and free copyright. This tool, designed in 1990 by The EuroQol Group (comprised of international multidisciplinary researchers devoted to measuring health status), was revised in 2005 and validated in 2011 [26, 27]. The questionnaire includes five dimensions: mobility, self-care, usual activities, pain/discomfort, anxiety/depression, and an overall visual analog scale. Importantly, it has been validated in patients with obesity and who have undergone obesity surgery, and is sensitive to change [28, 29]. In cases where the main goal of the study is related to QoL, however, an additional obesity-specific measure may be useful to assess this parameter in more depth. 
Alligier et al.: OBEDIS Core Variables Project

\section{Lifestyle and Behavior: Dietary Intake, PA and Sedentary Behavior, Sleep, Stress and Other Psychological Variables}

While human behaviors vary substantially and occur in a complex interplay with an individual's social and physical environments, characterization of specific behavior patterns is useful for predicting clinical outcomes. Discussed in this section are behaviors and lifestyle factors that affect energy balance, weight loss, and/or weight maintenance.

Dietary Intake

Minimal core set recommended variables:

- Dietary intake: EPIC-Norfolk FFQ or a region-specific validated FFQ (Food Frequency Questionnaire)

- Dietary quality: Dutch Healthy Diet index or region-specific validated index

- Emotional eating: DEBQ (Dutch Eating Behavior Questionnaire)

Expanded set recommended variables:

- Dietary intake: 3-day weighed food record

Eating behavior, defined as an individual's food and beverage consumption and habitual eating patterns [30], is a complex and important modifiable behavior that directly affects weight and nutritional status through the lifespan. In obesity, assessment of eating behavior is necessary given the dual burden of disease and potential undernutrition. Obesity interventions that target eating behavior mostly aim to decrease energy intake to induce negative energy balance - a necessary condition for weight loss. Modification of dietary intake is a well-known requirement for successful treatment of adult obesity [31]. The benefits of dietary interventions for obesity go beyond weight loss, since a body of evidence shows that changes in dietary quality per se may decrease the risk of various comorbid health conditions and even reduce all-cause mortality [32,33]. Dietary intake constitutes a critical factor that interfaces with genetic heterogeneity and metabolic phenotypes, resulting in different health outcomes; for example, dietary fat intake can interact with genotype and/or phenotype to affect the risk of obesity [34, 35]. In addition, dietary fatty acid exposure can also interact with sex and genes together to predict the development of the metabolic syndrome [36, 37].

Many dietitians and nutrition scientists recognize the need to move from populationbased nutrition to personalized subgroup-based nutrition [38]. Obesity is highly heterogeneous, so personalized or targeted interventions are warranted [39] but a major challenge is to determine which diet-related variables stratify individuals into groups that will respond to a given intervention.

For all adult trials on obesity interventions, regardless of whether they focus on diet, the OBEDIS group recommends assessing both dietary intake and overall diet quality. The OBEDIS group acknowledges, however, the particular difficulty of identifying dietary assessment tools applicable to the broad range of cultural and geographic groups across Europe. While obtaining data on energy, and macronutrient and micronutrient intake is a major objective, the various assessment tools that exist are each appropriate for a specific country or region.

Dietary intake is a detailed account of which foods and beverages are consumed, and in what quantities, during a set period of time. Initiatives exist (beyond the scope of these guidelines) that propose the most appropriate dietary assessment method in order to collect good quality dietary data, depending on the study objectives. The group recommends assessing this parameter in the minimal core set using a food frequency questionnaire (FFQ); the experts put forth the EPIC-Norfolk FFQ for consideration [40], while noting that the FFQ used in each trial should be validated according to the country in which it is being used. A 3-day weighed food record is appropriate for detailed studies where greater insights and links to biological readouts are required; such an assessment may capture short-term changes as a result of intervention. In the expanded set of variables (or depending on the study question) 
Alligier et al.: OBEDIS Core Variables Project

the experts recommend the use of a 3-day weighed food record, which is more suitable for detecting the effects of an intervention. Reviews like Dao et al. [41] can help researchers select and implement the most appropriate dietary assessment method(s) to collect highquality dietary data.

The group also recommends in the minimal core set an assessment of dietary quality, while acknowledging that the healthy eating indices applicable in Europe are linked with country-specific dietary guidelines and guidelines for PA. The Dutch Healthy Diet index [42, 43] was cited as a useful tool; however, the experts emphasize that the index used in a given trial must be adapted according to local guidelines and habits. The group also notes that in some contexts, it is important to use additional measures for tracking specific components of diet: for example, fiber intake or sugar-sweetened beverage consumption or the consumption of processed food.

The group agrees the nutrition community should invest in the design and validation of assessment tools for dietary intake (included validated smartphone apps) that improve upon the ones currently available. Dietary intake assessment is highly challenged by the lack of accurate biomarkers, particularly in relation to energy intake and macronutrient intake, whilst micronutrient status may be more feasible.

Biomarkers of dietary compliance were discussed by the OBEDIS experts. Such biomarkers are required to provide subjective insight in relation to habitual diet, as well as compliance to dietary interventions. However, those currently available have inherent limitations; for example, serum fatty acids only provide a short-term and limited assessment/reflection of dietary fatty acid intake. These biomarkers are not recommended for the minimal core set, but the experts note the critical importance for trials with free-living interventions of having an objective measure of compliance to identify nonresponse due to either noncompliance or lack of biological response.

When faced with stress, individuals exhibit differences in eating patterns: approximately $40 \%$ increase and $40 \%$ decrease their energy intake, while around $20 \%$ do not change [44]. Regardless of whether overall energy intake is increased, however, stress begets a shift toward choosing foods higher in sugar and fat. Hyper-palatable foods may act as a distress coping mechanism, particularly in those who have previously associated intake with relief [45]. Dieting constitutes a risk factor for emotional eating, since stress and negative affect can be consequences of energy restriction, and paradoxically, may lead to food-related coping strategies [46]. There may also be a biological basis for emotional eating, as individuals who exhibit this pattern demonstrate a blunted hypothalamic-pituitary-adrenal axis response to cortisol that leads to increased food intake [47].

Emotional eating is associated with current and prospective weight, and interacts with perceived stress, negative life events, and short sleep duration [47]. Greater weight loss success has been associated with decreased emotional eating score during a behavioral weight loss program [48]. Eating in response to distress may also influence the timing of meal consumption - and because recent studies have indicated that meal timing in relation to sleep phase is an important factor for weight regulation, clinical trials should capture individuals' tendency toward emotional eating. The recommended tool for assessing these behaviors in the OBEDIS minimal core set is the Emotional Eating Subscale of the Dutch Eating Behavior Questionnaire (DEBQ) - a clinically relevant questionnaire with good validation [49].

PA and Sedentary Behavior

Minimal core set recommended variables:

- PA: PA levels via accelerometry

- Sedentary behavior (SB): week day time and weekend day time via accelerometry; Paffenbarger Physical Activity Questionnaire 
Alligier et al.: OBEDIS Core Variables Project

- Physical fitness: cardiorespiratory fitness (CRF) via 6-min walk test and muscle strength via Southampton grip-strength measurement

Expanded set recommended variables:

- $\quad$ CRF: Chester step test

PA is any bodily movement produced by the contraction of skeletal muscles that results in energy expenditure (EE) above resting levels [50], while exercise is a subtype of PA: one that is planned, structured, repetitive, and designed to improve or maintain physical fitness, physical performance, or health [50].

PA helps adjust energy balance in those with obesity. Yet when diet is held constant, individuals in different BMI categories may experience different effects of PA on weight [51]. Overall, studies report inconsistent results on how increased PA (including exercise training) affects weight loss; however, an inverse association has been shown between PA and longterm weight gain [52], although it is recognized that relatively high levels of PA might be required. There is general agreement that a major benefit of PA in subjects with obesity is prevention of weight regain after weight loss [53].

Studies show PA attenuates many health risks that are associated with overweight or obesity, and importantly, numerous health benefits result from increased PA even with no weight loss or only modest weight loss [54]. Current evidence indicates that PA, at levels that are feasible to perform in subjects with overweight or obesity, only results in modest weight loss [52].

SB is defined as any waking behavior characterized by an EE equal to or lower than 1.5 metabolic equivalent tasks (or MET, with 1 MET representing EE by a subject at rest, sitting); this includes behaviors carried out while sitting, reclining, or lying [55]. Independent of PA levels, SB is associated with a higher risk of cardiometabolic disease and other complications. Decreasing SB is promoted in parallel with interventions that aim to increase habitual PA [55].

The OBEDIS group agrees on the importance of including both objective and subjective measures of PA and SB in each clinical trial. Objective data on both of these can be gathered most commonly using an accelerometer - a type of movement sensor that is feasibly used in large-scale studies to quantify PA intensity and duration as well as SB duration, including breaks in sedentary time, with minimal inconvenience to the participant. The group recommends this method while noting several limitations: when worn on the hip, accelerometers typically miss upper body movement; neither do they provide data on body posture nor data in cycling or aquatic activities [56]. The required accelerometer data comprises PA level as well as week day time in SB and weekend day time in SB. A subjective measure of PA and SB is also needed to add important information, such as the specific types of activities performed, the perceived level of exertion during exercise, and additional information about the context (place, time) of the PA. For these purposes, the group put forward a short questionnaire called the Paffenbarger Physical Activity Questionnaire. This widely used instrument is available in multiple languages and has ten questions that focus on moderate-to-vigorous PA, ranging from common activities such as stair climbing and walking to specific leisure activities [57].

In addition to PA and SB, physical fitness is an important patient characteristic that may also relate to outcomes of the intervention(s). Physical fitness is a physiological attribute determining a person's ability to perform muscle-powered work, and it has been defined as "the ability to carry out daily tasks with vigor and alertness, without undue fatigue, and with ample energy to enjoy leisure-time pursuits and respond to emergencies" [52]. One major component of physical fitness is CRF. High CRF is associated with greater longevity and reduced cardiovascular risk in all BMI categories [58, 59].

While the usual measure of CRF is maximal oxygen uptake $\left(\mathrm{VO}_{2}\right.$ max, or maximal aerobic power) during an exercise test [60], requirements for specialized equipment and expertise 
Alligier et al.: OBEDIS Core Variables Project

render it impractical for the minimal core set. The OBEDIS experts instead recommend the use of the 6-min walk test [61], a field submaximal exercise test for assessment of physical function that requires a 30-m hallway and no specialized training or equipment. The test measures the distance an individual can quickly walk on a flat, hard surface over a period of $6 \mathrm{~min}$, and it can be used to predict $\mathrm{VO}_{2} \max [62,63]$. The expanded set, however, may include the Chester step test as a measure of CRF: in this validated assessment of aerobic capacity, the participant is asked to step on and off an elevated platform in time with an audible metronome beat [64].

Another important component of physical fitness is muscular fitness. A measure of muscle strength, as an important component of muscular fitness, is therefore also recommended for the minimal core set, since the evidence in aggregate shows that muscle strength is associated with reduced mortality in all BMI categories and that resistance training (designed to increase muscle strength), even without weight loss, improves health risk [53]. More importantly, weight loss treatments may be associated with decreases in muscle strength, especially if the treatment does not include exercise. The Southampton grip-strength measurement is chosen for this purpose [65].

Given these recommendations, the group notes an added value of the assessment methods in the minimal core set: some of the chosen methods are useful for assessing several variables. This is the case for the use of accelerometers to assess both PA and sleep behaviors; grip strength to measure both muscular fitness and (in the expanded set) sarcopenia; and the 6-min walk test to predict CRF.

Habitual PA, SB, and physical fitness all must be measured at baseline (before any exercise training or intervention occurs) and at the end of an intervention; in trials longer than 6 months, these variables should be measured every 6 months.

\section{Sleep}

Minimal core set recommended variables:

- Sleep duration and timing

- Presence of sleep apnea: STOP-BANG

Expanded set recommended variables:

- $\quad$ Sleep duration and timing: accelerometry

Sleep is influenced by the circadian clock - a self-sustained molecular oscillator, which aligns endogenous rhythms with daily exogenous signals to coordinate metabolism and behavior [66]. Ample data show mistimed sleep contributes to "chronodisruption" [67] or "circadian-phase misalignment" [68] and promotes weight-related pathologies [69, 70].

Commonly, sleep disruption occurs because of atypical work schedules: night shift work patterns are associated with the risk of overweight/obesity - especially abdominal obesity - and permanent night shifts appear to confer a higher risk than rotating night shifts [71]. A lesser degree of chronodisruption called "social jetlag," however, can result from social activities and has been associated with an increased BMI [72]. Given these data, the OBEDIS group recommends systematically recording whether individuals work on atypical schedules (specifically: the presence of night shift work and permanent night work), and whether they experience social jetlag. Although the Munich Chronotype Questionnaire (MCTQ) is sometimes used for these purposes, the OBEDIS group recommends a shorter custom assessment (see supplementary material) for patients to self-administer. Quantitative sleep data acquired from an accelerometer may be used (as part of the expanded set) in trials where resources allow.

Prolonged wakefulness and sleep deprivation are hallmarks of modern lifestyles. Across cross-sectional and longitudinal studies, individuals' sleep duration shows a somewhat inconsistent pattern of association with obesity [73]. Experimental data suggest that sleep 
Alligier et al.: OBEDIS Core Variables Project

restriction increases food intake and alters EE [74]. The OBEDIS group advocates for a basic assessment of sleep duration in the minimal core set. Specific questionnaires exist that capture various dimensions of sleep, including sleep duration, but many are subject to copyright restrictions and/or lack validated translations into different languages. For assessing sleep duration, the OBEDIS group recommends a custom, self-administered questionnaire (shown below).

In individuals with obesity, disordered breathing during sleep is prevalent. Well-documented is the idea that obstructive sleep apnea (OSA) overlaps with obesity-related risks [75] and impacts metabolic risk [76]. Use of the OSA therapy continuous positive airway pressure (CPAP) may also change energy balance or metabolism [77], with potentially positive effects on glycemic control [78]. The presence of OSA and the use of CPAP should therefore be assessed. While the gold-standard objective measure of OSA is the apnea-hypopnea index with nocturnal polysomnography, the OBEDIS group recommends subjective assessment using a brief questionnaire called the STOP-BANG [79]. This questionnaire, which is freely available, was created to screen for symptoms of OSA in surgical patients and in all individuals. It can be completed in approximatively $1 \mathrm{~min}$ and has good predictive ability for mild, moderate, and severe OSA [80]. CPAP use may be assessed using a custom questionnaire item.

Stress and Other Psychological Variables

Minimal core set recommended variables:

- Perceived stress: Perceived Stress Scale (PSS)

Previous research has indicated the necessity for simultaneous assessment of sleep and stress in trials on obesity [81]. Poor sleep and emotional stress are predictors of incident obesity and may have an additive role [82]. Not only does perceived stress associate with BMI, waist circumference, and serum triglyceride level [83], but also, those with poor sleep and incident obesity appear to have the greatest emotional stress and the shortest subjective sleep duration [84].

Perceived stress is the degree to which situations in life are appraised as stressful by the individual. The expert group recommends subjective assessment of individuals' stress levels via the PSS [85]. As the most widely used psychological instrument for measuring the perception of stress, the scale includes direct queries about a patient's current levels of experienced stress. The items on the questionnaire are general, easy to grasp, and require a total of 2 min for completion. An additional advantage of the tool is the availability of validated versions in many languages.

\section{Subject Characteristics: Anthropometry, Body Composition, EE, and Hormonal Status}

All trials involving individuals with obesity include measures of participants' characteristics, including anthropometric measures, body composition, and/or EE. Aspects of hormonal status are also important characteristics to consider in trials, as detailed below.

Anthropometry, Body Composition, and EE

Minimal core set recommended variables:

- Weight and BMI

- Anthropometry (waist, hip, neck circumference)

- Fat mass and fat-free mass: dual energy X-ray absorptiometry (DXA)

Expanded set recommended variables:

- EE: open-circuit indirect calorimetry

The WHO defines obesity as "a condition of abnormal or excessive fat accumulation in adipose tissue, to the extent that health may be impaired" [86]. In clinical trials on obesity, researchers must quantify this increased adiposity in a way that allows comparisons between 
Alligier et al.: OBEDIS Core Variables Project

subjects, and over time in the same subject. Patient-reported data are not adequate for these purposes. The OBEDIS experts acknowledge that the study of body composition assessment methods is rapidly moving forward, far beyond basic calculations of BMI, and this may present an important opportunity for identifying precise body composition subgroups that may respond predictably to an intervention.

BMI - calculated from measures of a subject's height and weight - is the simplest and most frequent way of classifying an individual as underweight, normal weight, overweight, or obese, and is therefore recommended for inclusion in the minimal core set. Although the relationship between BMI and all-cause mortality has been confirmed [87], BMI as a "surrogate measure" of obesity does not directly capture large interindividual variation in excess adipose tissue. This makes BMI misleading for individuals who exhibit differences in proportions of lean body mass and fat mass (for instance, elite athletes and those with sarcopenia) [88]. Indeed, going beyond a patient's BMI adds valuable additional information about health [8991]. Recent work shows it is the excess fat that constitutes a risk factor for a range of comorbid diseases: type 2 diabetes (T2D), ischemic heart disease, hyperlipidemia, sleep apnea, certain forms of cancer, and others [92].

Further anthropometric measures - waist, hip, and neck circumferences - are recommended in all clinical trials focusing on obesity, as ways to assess subjects' fat distribution. Ample evidence shows increased central or android fat distribution (assessed via waist-toheight ratio) is associated with greater risk to health $[93,94]$ compared to more peripheral or gynoid fat distribution. Adding waist circumference to other anthropometric measures is valuable for predicting metabolic phenotypes [95] and a rationale even exists for how variables that include waist circumference directly affect intervention response [96]. Waist-tohip ratio predicts cardiovascular morbidity and mortality in those with obesity and T2D [9799]. In addition, neck circumference has been shown valuable for identifying excess body weight $[100,101]$ and associates with the presence or severity of different comorbidities [102-104].

Many options exist for more precise measurements of body composition. Available methods, each with their pros and cons, include bioelectrical impedance analysis (BIA), magnetic resonance imaging, computerized tomography scan, air displacement plethysmography (BOD POD), underwater weighing, and DXA. Body weight, BMI, or variables derived from weight alone are unable to distinguish between fat-free mass and fat mass, yet these components have specific medical relevance: increased fat-free mass may be found in athletes, who are not obese despite a high body weight/BMI; decreased fat-free mass is characteristic of a pathological condition called sarcopenia (or sarcopenic obesity), which needs to be detected; and fat-free mass is a determinant of EE (see below). Meanwhile, the visceral component of total body fat has unique physiological characteristics, which influence diseaserelated processes in the body [105]. Increased visceral adipose tissue in those with obesity is associated with an increased risk of metabolic (glucose intolerance, T2D) and cardiovascular disease (CVD).

The OBEDIS group agrees that precisely capturing the amount and distribution of body fat is required for the minimal core set of variables. At present, however, no easy methods exist for assessment. BOD POD and BIA are two-compartment models (capturing fat mass and fat-free mass), while DXA is a three-compartment method (dividing the body into fat mass, lean body mass, and bone mineral content). This relatively accurate, noninvasive method enables rapid measurement of percent body fat, although it remains dependent on several assumptions (namely, the constancy of fat-free mass composition) and exposes participants to a small dose of ionizing radiation. But because DXA is validated for those with obesity, it is the OBEDIS group's recommendation. 
The use of DXA, a method that requires specialized equipment, is an exception to the general principle of simplicity in the OBEDIS minimal core set, but the group agrees that the potential predictive value of DXA-generated data is sufficiently great to enable rapid progress in the field. In cases where trial limitations in budget, equipment, or expertise render it impossible to incorporate DXA, the group recommends BIA or plethysmography as an alternative to measuring fat mass and fat-free mass. Overall, the expert group concurs that the field needs more research and development on easy and inexpensive tools for precise measurements of body composition.

Energy balance in obesity may be important for prediction of intervention outcomes [106]. EE is one component of energy balance, and hence, highly relevant for evaluating body weight changes. A subject's EE is likely to change in the course of an intervention, as it can vary with changes in body weight [107] or fat-free mass; changes in the composition of body weight gained or lost; adaptive thermogenesis (thyroid hormones, sympathetic nervous system, brown adipose tissue); and pharmacologic agents [108].

Twenty-four-hour EE is the sum of basal metabolic rate (BMR), adaptive thermogenesis (food, thermoregulation, etc.), and PA/exercise thermogenesis; it can be measured in freeliving individuals with doubly labelled water, but this method is expensive and restricted to a few specialized centers. Resting EE can be measured by indirect calorimetry - but again, this method is not feasible in all centers, and accurate measurements require very strict conditions (overnight fast; no PA prior to measurement, requiring that measurement is done on inpatients; thermoneutrality, etc.). BMR varies according to body composition (mainly fat-free mass), and hormonal status (thyroid hormones, sympathetic nervous system/catecholamines, brown adipose tissue). BMR can be predicted with equations based on body weight or body composition:

$\mathrm{BMR}=\mathrm{a} \cdot$ body weight $+\mathrm{b}$ (where $\mathrm{a}$ and $\mathrm{b}$ are different for males and females); or

$\mathrm{BMR}=\mathrm{a} \cdot$ fat-free mass $+\mathrm{b}$ (where $\mathrm{a}$ and $\mathrm{b}$ are identical for both males and females).

Expressing results as kcal expended per kg body weight or per kg fat-free mass invariably underestimates values in overweight/obese individuals and should not be used. Results should instead be expressed as percentages of predicted value based on validated equations (Mifflin Jeor or others; see supplementary materials).

EE is an essential feature for metabolic phenotyping, but direct measurement of EE should be included in the OBEDIS expanded set rather than in the minimal core set. The energy requirements of individuals included in a study can instead be predicted based on the BMR prediction equations above, multiplied by a PA level of 1.1-1.9 for PA level [109]. Measurement of EE may nonetheless be highly relevant in some mechanistic studies, since variations in BMR may occur during interventions due to changes in body weight/fat-free mass (body composition-dependent changes) and changes in tissue (fat-free mass) metabolic activity. Such measurements are best done by open-circuit indirect calorimetry using standardized procedures. Simultaneous measurement of body composition is strongly recommended for data interpretation.

Hormonal Status

Minimal core set recommended variables:

- Thyroid-stimulating hormone (TSH): third generation TSH assay

- Menopausal status (in females), current medications

Expanded set recommended variables:

- Follicle-stimulating hormone (FSH) and luteinizing hormone (LH) (in women)

- Androgens: mass spectrometry-based assays 
Alligier et al.: OBEDIS Core Variables Project

Endocrine and gynecological system alterations can occur in obese individuals, and many different measurements give insights into these complications; these include markers of thyroid status, that can be related to regulation of energy balance, and markers of gonadal axis in both sexes $[110,111]$. Among these hormones, the group recommends the measurement of TSH to assess thyroid function; FSH and LH may be used in the expanded set to confirm, when necessary, menopausal status in women. In both males and females, androgens might provide valuable additional information; however, should their measurement be included, it should be mandatorily accomplished by mass spectrometry-based assays [112].

A panel of peptides and cytokines is usually characterized in studies focusing on obesity, including leptin, as a marker of body fat; adiponectin, as a predictor of metabolic dysregulation; tumor necrosis factor alpha and interleukin-6, as markers of inflammation; ghrelin, as a hunger signal; glucagon-like peptide- 1 and peptide $Y Y$ as a measure of satiation signal function. Consequently, measurement of each of these hormones may be included in clinical trials for obesity, according to the specific research question. However, preanalytical and analytical issues related to the measurement of most of these substances dramatically affect the consistency of the results. Assay standardization and harmonization among labs are urgently needed to generate normative values. In addition, mass spectrometry-based assays for the quantitative and qualitative (isoforms, posttranslational modifications, etc.) assessment of peptide hormones are regarded as promising for their thorough characterization; however, the introduction of such techniques into routine clinical labs does not appear feasible in the near future.

\section{Complications: T2D, Cardiovascular Risk, Liver Disease, and Other Long-Term Obesity Complications}

The many complications of obesity are of interest because of their associations with poorer overall health and with more complex clinical management. These comorbid conditions, and the medications taken to ameliorate them, may affect response to intervention. The major comorbid conditions in obesity are addressed in this section.

Type 2 Diabetes

Minimal core set recommended variables:

- Fasting glycemia (two measurements)

- Hemoglobin A1c: HPLC-CE or HPLC-MS

- Fasting insulin and insulin-derived insulin sensitivity indices

- Family history of diabetes

Expanded set recommended variables:

- Hyperinsulinemic-euglycemic clamp

Obesity is associated with alterations in normal endocrine and metabolic functions, leading to a number of pathological conditions: among these, T2D - affecting around 30-40\% of obese individuals [113]. Although metabolically healthy obese individuals exist, epidemiological evidence shows a high incidence of metabolic syndrome in those with obesity [114]. In patients with both obesity and T2D, interventions that lead to successful weight management substantially improve outcomes related to metabolic control [115]. Response to interventions may also be modified by the use of various antidiabetic medications, which might affect weight either positively or negatively [113].

The OBEDIS group recommends including several T2D-related variables in all clinical trials on obesity interventions: two measurements of fasting plasma glucose for assessing T2D, hemoglobin A1c (HbA1c) for screening and monitoring of glycemic control, and fasting insulin as a surrogate marker for insulin resistance as well as indicating the secretory capacity of the beta cells. HbA1c measurement is recommended both for assessing blood glucose 
Alligier et al.: OBEDIS Core Variables Project

control in people with diagnosed T2D, and for diagnosing the disease or its early stages ("prediabetes"). The group agrees that C-peptide could take the place of fasting insulin as a marker of remaining insulin secretion. Further, insulin-derived insulin sensitivity indices should be calculated [116]: Homeostatic Model Assessment of Insulin Resistance (HOMA-IR) represents the presence and extent of insulin resistance; whereas HOMA-beta reflects beta cell function. Both calculations are mainly used in clinical studies. Several additional factors related to T2D are important to know - the individual's family history of T2D (to indicate possible genetic risk), as well as current medication and dosages. Recommendations on specific methods for each of these parameters are detailed in Table 1. There are more invasive measures of insulin secretion and sensitivity (hyperinsulinemic-euglycemic clamp, intravenous glucose tolerance test, etc.) and more comprehensive measures of key aspects of metabolic flexibility, but these tests are not feasible for all large-scale clinical interventions.

Cardiovascular Risk

Minimal core set recommended variables:

- Smoking habits

- Blood pressure and heart rate: automatic blood pressure device

- Total cholesterol, high-density lipoprotein cholesterol, triglyceride

- Inflammation: C-reactive protein (CRP)

- Heart electrical activity: 1- to 5-min electrocardiography (ECG)

- CRF: 6-min walk test

Individuals with obesity often exhibit disordered vascular and heart function, and an elevated risk of CVD. Intervention strategies may be modified by the presence of CVD or its various risk factors [117].

Most CVD risk is driven by age plus three other major CVD risk factors in addition to diabetes; namely, high cholesterol, high blood pressure, and smoking, together accounting for about $80 \%$ of population-attributable risk [118]. Cardiovascular risk algorithms exist [119122], but due to the imprecise estimates they provide and the factors that are included in these algorithms, they may not prove useful in the context of short-term interventions for obesity. While risk scores were not included in the minimal core set, the OBEDIS group proposes measuring smoking status as well as several parameters related to vascular and cardiac function, which may help, now and in the future, to stratify individuals in order to optimize intervention outcomes.

Assessment of current smoking habits in the minimal core set is achieved using two custom questions: number of cigarettes per day and duration of smoking.

Related to vasculature (atherosclerosis), the group recommended obtaining data on selected serum biomarkers: total cholesterol, high-density lipoprotein cholesterol, triglycerides, and high-sensitivity CRP (hsCRP). Fasting hsCRP is included as a surrogate marker of inflammation, and CRP appears to be one of the best-established CVD risk markers [123-127] while having the advantage of being analyzed in a standardized and relatively inexpensive way. Additional measures relevant to CVD, including blood glucose and insulin concentrations, which capture insulin resistance and beta-cell function [128], are covered in the T2D section. The adipokine interleukin-6 also seems promising [129], and is recommended for the expanded set, with the recommendations about its measurement proposed in the supplementary materials.

Among the variables related to cardiac function that could potentially modulate response to interventions for obesity, the following are recommended by the OBEDIS group for assessment: blood pressure, cardiopulmonary function, and electrical activity of the heart as measured by ECG. It is well-established that blood pressure may be modified by certain interventions, with weight loss causing important decreases in blood pressure [130]. Despite 
somewhat limited reproducibility for automatic blood pressure devices, the group recommends using these in order to reduce human error. As an indirect but validated way to assess CRF, the group identifies the 6-min walk test [131-134] rather than the determination of maximal aerobic capacity $\left(\mathrm{VO}_{2} \mathrm{max}\right)$, which is expensive and has a poor association with fat mass and the loss thereof [135-137]. Finally, the group recommends performing a 1- to 5-min ECG as detailed in Table 1. Although not fully validated for hard endpoints, 1- to 5-min ECG is often used in small intervention clinical trials [138] and predicts cardiovascular death; thus, it may be used as a noninvasive means of risk stratification [139].

Assessing the presence of OSA is also essential, since OSA is associated with hypertension and an increased risk for CVD and T2D [140]. These measures are detailed in the section on sleep behaviors.

\section{Liver Disease}

Minimal core set recommended variables:

- Nonalcoholic fatty liver disease (NAFLD) fibrosis score (NFS) and fibrosis-4 index (FIB-4):

ALT, AST, GGT, platelet count, and albumin from blood

- Alcohol intake: WHO AUDIT questionnaire

Obesity comes with an increased risk of different forms of NAFLD: steatohepatitis (increased liver triglycerides), possibly progressing to fibrosis (irreversible scarring of the liver) [141]. Tracking the occurrence of these liver conditions is deemed important for the minimal core set, as these conditions may affect a subject's response to intervention. To detect fibrosis noninvasively, most guidelines $[142,143]$ recommend using the FIB-4 or the NFS, both of which are low cost and straightforward.

Given the relationship of alcohol intake to liver disease, the OBEDIS group also recommends a brief assessment of alcohol intake using the WHO's AUDIT questionnaire [144].

Other Long-Term Obesity Complications: Osteoarthritis and Cancer

Minimal core set recommended variables:

- QoL: EQ-5D-5L

Expanded set recommended variables:

- $\quad$ Pain-related physical functioning: WOMAC VA 3.0

Over the long term, besides the significantly increased risk of CVD and T2D, obesity confers an increased risk for several other conditions: major medical complications (cancer), and functional complications (arthrosis). Data on these conditions are part of a comprehensive assessment of the obesity phenotype.

Obesity increases the risk for osteoarthritis, a degenerative condition of joint pain and dysfunction [145]. The presence of this condition is normally assessed through specific selfadministered validated osteoarthritis questionnaires. But (pain-related) physical functioning is the most important factor related to osteoarthritis that may change with an intervention [146], and the OBEDIS group decided this factor is adequately assessed by an overall QoL questionnaire. The addition of a specific osteoarthritis questionnaire to the QoL questionnaire recommended above would provide marginal improvement in predictive ability. In the expanded set of variables, however, investigators may want to include the Western Ontario and McMaster Universities (WOMAC VA 3.0) osteoarthritis index, a self-report questionnaire covering hip and knee osteoarthritis [147].

Those with obesity experience cancer at a higher rate than the general population [148] and a patient's history of cancer may be relevant to the exclusion criteria in a clinical trial. Once a patient is enrolled in a trial, however, investigators may want to track cancer occurrence. The OBEDIS group decided that including cancer data in the minimal core set was not necessary; because of the long delay before cancer occurrence, the following data need only 
Alligier et al.: OBEDIS Core Variables Project

be collected in cohorts with more than 5 or 10 years of follow-up: date of diagnosis and cancer type (according to the International Classification of Diseases). The data should be obtained from medical records where possible and validated by independent medical experts.

\section{Future Medical Practice}

Several areas of analysis have the potential to advance precision medicine within the field of obesity: tissue phenotyping, as well as genetics, and omics.

It is already known that researchers may gain insights into the molecular underpinnings of variability in weight loss by precisely analyzing different body tissues in individuals with obesity [149]: apart from components of blood, urine, and stool, this may include biopsies and/or assessments of white adipose tissue, skeletal muscle, and the liver. Precise phenotyping of patients by tissue analysis is a promising area within the field of obesity; some studies have successfully used this approach to identify subgroups of participants that have increased susceptibility to obesity or that will predictably respond to a treatment $[150,151]$. However, the complexity of these methods rules them out for the minimal core set at present.

In the future, patients may be stratified based on the presence of specific genetic markers. Data from family, twin, and adoption studies show that both body weight (40-70\%) and body fat distribution are highly heritable [152]. Heritability also seems to play a role in the nature, magnitude, and/or timing of response to obesity interventions [153]: studies have shown genetic influences on dietary interventions $[154,155]$ and heritability of response to bariatric surgery (Roux-en-Y) [156]. Obesity-related gene expression may be attenuated by PA. This field is expected to advance rapidly over the next few years and zero in on very specific genetic markers for patient stratification.

Beyond human genes, advances in high-throughput technologies for analysis of biologic molecules have created the potential for defining the biological characteristics of those with obesity with great precision. New omics technologies enable examination, not only of a patient's genome, but also of complete sets of transcripts, proteins, and metabolites. Analyses that fall under the category of omics are those that provide "a comprehensive, or global, assessment of a set of molecules" [157]: genomics, epigenomics (reversible modifications of DNA or DNA-associated proteins across the genome), proteomics, metabolomics (small molecule types), microbiomics, lipidomics, transcriptomics, and others. Already, findings from omics studies have identified important avenues of research in obesity: for instance, epigenomic studies have mechanistically linked aspects of the environment before conception with the probability of becoming obese later in life $[158,159]$, while weight loss induced by gastric bypass surgery affects a patient's DNA methylation and gene expression profile [160].

The analyses mentioned above are key components of certain obesity intervention studies, depending on their aims. The OBEDIS group considered the pros and cons of including genetic and omics data, as well as tissue analyses, in the minimal core set for all obesityfocused clinical trials; the group concludes that at present, the ability of these tests to explain variability in weight loss is not great enough to justify the added costs. The group strongly suspects, however, that as costs fall and evidence increases, researchers will soon have adequate justification for including such analyses in all trials.

In anticipation of the probability that certain blood measurements may yield new insights in the near-term future, biobanking is highly recommended by the group - whole blood where possible, but at a minimum, samples of whole blood dried on paper. Dried blood spots are suitable for many potential future measurements, and also have the advantages of easy and low-cost collection and storage.

The OBEDIS group agrees that consent is another important issue to address for this field: a challenge is to develop SOPs around consent, which will allow sharing and reuse of 
Alligier et al.: OBEDIS Core Variables Project

omics and other data over the long term and as new discoveries are made. The group envisions a set of consent-related SOPs implemented across Europe, adapted to local circumstances.

\section{Conclusion}

The expert consensus detailed herein represents a practical advancement in the field of obesity research - with the group members supporting the adoption of these variables in future clinical trials, collected systematically either before or both before and after intervention. The group fully expects to add further variables to this minimal core set as more data become available in each of the identified domains or remove variables if they do not impact differential treatment response. Basic and preclinical research should, of course, continue in tandem, building a larger context for informing better intervention strategies and identifying the appropriate adult patient groups for each specific intervention.

The translational potential of the work begun here is therefore of high value: over time, this project should enable more efficient convergence of evidence to support better care for those with obesity. The OBEDIS group sees the ability to pool datasets and compare very large numbers of trial participants as key to the advancement of "precision" or "personalized" medicine. In the future, when a clinician encounters a newly referred adult patient with obesity, he or she will be able to group the patient according to baseline characteristics and suggest a tailored intervention plan, backed by robust data.

The OBEDIS workshop and the resulting guidelines, achieved only through the support of EASO, represent an historic collaboration in the field of obesity in Europe. The experts welcome feedback that will help these measures to be widely adopted throughout the field.

\section{Disclosure Statement}

K. Clément is a consultant for Danone Research and LNC therapeutics for work unassociated with the present study. M. Neovius has received advisory board fees from Itrim and Ethicon Johnson \& Johnson. L. Tappy received a research grant from Soremartec Italy srl and speaker's fees from Soremartec Italy srl and Nestlé AG, Switzerland. No other authors have conflicts of interest to declare.

\section{Funding Sources} Life.

This initiative was funded by the Joint Programming Initiative Heathy Diet for Healthy

\section{Author Contributions}

All authors contributed to the guidelines described in this paper. M. Alligier and M. Laville led the initiative with J. Bouwman, K. Clément, and D. Langin. K. Campbell prepared the manuscript. 
Alligier et al.: OBEDIS Core Variables Project

\section{References}

1 World Health Organization. WHO/Europe approaches to obesity [Internet]. 2018 [cited 2018 Nov 11]. Available from: http://www.euro.who.int/en/health-topics/noncommunicable-diseases/obesity/obesity

23 Most Important Types of Biological Variables [Internet]. 2019 [cited 2019 Mar 12]. Available from: http:// www.yourarticlelibrary.com/environment/3-most-important-types-of-biological-variables/3791

3 MacLean PS, Rothman AJ, Nicastro HL, Czajkowski SM, Agurs-Collins T, Rice EL, et al. The Accumulating Data to Optimally Predict Obesity Treatment (ADOPT) Core Measures Project: rationale and Approach. Obesity (Silver Spring). 2018 Apr;26 Suppl 2:S6-15.

4 Hebebrand J, Holm JC, Woodward E, Baker JL, Blaak E, Durrer Schutz D, et al. A Proposal of the European Association for the Study of Obesity to Improve the ICD-11 Diagnostic Criteria for Obesity Based on the Three Dimensions Etiology, Degree of Adiposity and Health Risk [Internet]. Obes Facts. 2017;10(4):284-307. [cited 2018 Dec 27] Available from: http://www.ncbi.nlm.nih.gov/pubmed/28738325

5 Pulgarón ER. Childhood obesity: a review of increased risk for physical and psychological comorbidities [Internet]. Clin Ther. 2013 Jan;35(1):A18-32. [cited 2019 Mar 26] Available from: http://www.ncbi.nlm.nih. gov/pubmed/23328273

6 Stokes A. Using maximum weight to redefine body mass index categories in studies of the mortality risks of obesity [Internet]. Popul Health Metr. 2014 Mar;12(1):6. [cited 2019 Mar 26] Available from: http://www. ncbi.nlm.nih.gov/pubmed/24636105

7 Stafford M, Hemingway H, Marmot M. Current obesity, steady weight change and weight fluctuation as predictors of physical functioning in middle aged office workers: the Whitehall II Study [Internet]. Int J Obes Relat Metab Disord. 1998 Jan;22(1):23-31. [cited 2019 Mar 26] Available from: http://www.ncbi.nlm.nih. gov/pubmed/9481596

8 Latner JD, Ciao AC. Weight-loss history as a predictor of obesity treatment outcome: prospective, long-term results from behavioral, group self-help treatment [Internet]. J Health Psychol. 2014 Feb;19(2):253-61. [cited 2019 Jan 7] Available from: http://www.ncbi.nlm.nih.gov/pubmed/23297394

9 Mackie GM, Samocha-Bonet D, Tam CS. Does weight cycling promote obesity and metabolic risk factors? [Internet]. Obes Res Clin Pract. 2017 Mar - Apr;11(2):131-9. [cited 2019 May 13] Available from: http://www. ncbi.nlm.nih.gov/pubmed/27773644

10 Zhang S, Rattanatray L, Morrison JL, Nicholas LM, Lie S, McMillen IC. Maternal obesity and the early origins of childhood obesity: weighing up the benefits and costs of maternal weight loss in the periconceptional period for the offspring. Exp Diabetes Res. 2011;2011:585749.

11 Lane M, Zander-Fox DL, Robker RL, McPherson NO. Peri-conception parental obesity, reproductive health, and transgenerational impacts [Internet]. Trends Endocrinol Metab. 2015 Feb;26(2):84-90. [cited 2019 Mar 26] Available from: http://www.ncbi.nlm.nih.gov/pubmed/25523615

12 Neovius M, Bruze G, Jacobson P, Sjöholm K, Johansson K, Granath F, et al. Risk of suicide and non-fatal selfharm after bariatric surgery: results from two matched cohort studies. Lancet Diabetes Endocrinol. 2018 Mar; 6(3):197-207.

13 Ng WL, Peeters A, Näslund I, Ottosson J, Johansson K, Marcus C, et al. Change in Use of Sleep Medications After Gastric Bypass Surgery or Intensive Lifestyle Treatment in Adults with Obesity [Internet]. Obesity (Silver Spring). 2017 Aug;25(8):1451-9. [cited 2019 Feb 3] Available from: http://www.ncbi.nlm.nih.gov/ pubmed/28660652

14 Cohen AK, Rai M, Rehkopf DH, Abrams B. Educational attainment and obesity: a systematic review [Internet]. Obes Rev. 2013 Dec;14(12):989-1005. [cited 2019 Mar 26] Available from: http://www.ncbi.nlm.nih.gov/ pubmed/23889851

15 Connelly R, Gayle V, Lambert PS. A review of educational attainment measures for social survey research. Methodol Innov. 2016 Apr; 9:1-11.

16 World Health Organization. WHOQOL: Measuring Quality of Life [Internet]. 2014 [cited 2018 Nov 25]; Available from: http://www.who.int/healthinfo/survey/whoqol-qualityoflife/en/

17 International Classification of Impairments, Disabilities, and Handicaps [Internet]. 1980 [cited 2018 Nov 27]. Available from: http://apps.who.int/iris/bitstream/handle/10665/41003/9241541261_eng.pdf?sequence $=1$

18 World Health Organization. Constitution of WHO: Principles [Internet]. 2016 [cited 2018 Nov 23]; Available from: https://www.who.int/about/mission/en/

19 Engel GL. The need for a new medical model: a challenge for biomedicine [Internet]. Science. 1977 Apr; 196(4286):129-36. [cited 2018 Nov 23] Available from: http://www.ncbi.nlm.nih.gov/pubmed/847460

20 Falissard B. Mesurer la subjectivité en santé Perspective méthodologique et statistique. 2nd ed. Amsterdam: Elsevier/Masson; 2008.

21 Fuller NR, Carter H, Schofield D, Hauner H, Jebb SA, Colagiuri S, et al. Cost effectiveness of primary care referral to a commercial provider for weight loss treatment, relative to standard care: a modelled lifetime analysis [Internet]. Int J Obes. 2014 Aug;38(8):1104-9. [cited 2019 Jun 4] Available from: http://www.ncbi.nlm.nih. gov/pubmed/24301133

22 Karlsson J, Taft C, Rydén A, Sjöström L, Sullivan M. Ten-year trends in health-related quality of life after surgical and conventional treatment for severe obesity: the SOS intervention study [Internet]. Int J Obes. 2007 Aug;31(8):1248-61. [cited 2019 Jun 4] Available from: http://www.ncbi.nlm.nih.gov/pubmed/17356530 
23 Machin D, Fayers P. Quality of life : the assessment, analysis and interpretation of patient-reported outcomes. Hoboken: Wiley; 2013.

24 Duval K, Marceau P, Pérusse L, Lacasse Y. An overview of obesity-specific quality of life questionnaires [Internet]. Obes Rev. 2006 Nov; 7(4):347-60. [cited 2019 Jan 16] Available from: http://www.ncbi.nlm.nih. gov/pubmed/17038129

25 Fontaine KR, Barofsky I. Obesity and health-related quality of life [Internet]. Obes Rev. 2001 Aug;2(3):173-82. [cited 2018 Nov 23] Available from: http://www.ncbi.nlm.nih.gov/pubmed/12120102

26 Herdman M, Gudex C, Lloyd A, Janssen M, Kind P, Parkin D, et al. Development and preliminary testing of the new five-level version of EQ-5D (EQ-5D-5L) [Internet]. Qual Life Res. 2011 Dec;20(10):1727-36. [cited 2018 Nov 27] Available from: http://www.ncbi.nlm.nih.gov/pubmed/21479777

27 Van Reenen M, Janssen B. EQ-5D-5L User Guide Basic information on how to use the EQ-5D-5L instrument [Internet]. 2015 [cited 2018 Nov 27]. Available from: https://euroqol.org/wp-content/uploads/2016/09/ EQ-5D-5L_UserGuide_2015.pdf

28 Tarride JE, Breau R, Sharma AM, Hong D, Gmora S, Guertin JR, et al. The Effect of Bariatric Surgery on Mobility, Health-Related Quality of Life, Healthcare Resource Utilization, and Employment Status. Obes Surg. 2017 Feb; 27(2):349-56.

29 Fermont JM, Blazeby JM, Rogers CA, Wordsworth S; By-Band-Sleeve Study Management Group. The EQ-5D-5L is a valid approach to measure health related quality of life in patients undergoing bariatric surgery. PLoS One. 2017 Dec 18;12(12):e0189190.

30 Lytle LA, Nicastro HL, Roberts SB, Evans M, Jakicic JM, Laposky AD, et al. Accumulating Data to Optimally Predict Obesity Treatment (ADOPT) Core Measures: behavioral Domain. Obesity (Silver Spring). 2018 Apr;26 Suppl 2:S16-24.

31 Raynor HA, Champagne CM. Position of the Academy of Nutrition and Dietetics: Interventions for the Treatment of Overweight and Obesity in Adults. J Acad Nutr Diet. 2016 Jan;116(1):129-47.

32 Ma C, Avenell A, Bolland M, Hudson J, Stewart F, Robertson C, et al. Effects of weight loss interventions for adults who are obese on mortality, cardiovascular disease, and cancer: systematic review and meta-analysis. BMJ. 2017 Nov;359:j4849.

33 den Boer AT, Herraets IJ, Stegen J, Roumen C, Corpeleijn E, Schaper NC, et al. Prevention of the metabolic syndrome in IGT subjects in a lifestyle intervention: results from the SLIM study [Internet]. Nutr Metab Cardiovasc Dis. 2013 Nov;23(11):1147-53. [cited 2019 May 9] Available from: http://www.ncbi.nlm.nih.gov/ pubmed/23462149

34 Yubero-Serrano EM, Delgado-Lista J, Tierney AC, Perez-Martinez P, Garcia-Rios A, Alcala-Diaz JF, et al. Insulin resistance determines a differential response to changes in dietary fat modification on metabolic syndrome risk factors: the LIPGENE study [Internet]. Am J Clin Nutr. 2015 Dec;102(6):1509-17. [cited 2019 Mar 28] Available from: http://www.ncbi.nlm.nih.gov/pubmed/26561628

35 Phillips CM, Kesse-Guyot E, McManus R, Hercberg S, Lairon D, Planells R, et al. High dietary saturated fat intake accentuates obesity risk associated with the fat mass and obesity-associated gene in adults [Internet]. J Nutr. 2012 May;142(5):824-31. [cited 2018 Dec 15] Available from: http://www.ncbi.nlm.nih.gov/pubmed/ 22457394

36 Phillips CM, Goumidi L, Bertrais S, Field MR, McManus R, Hercberg S, et al. Dietary saturated fat, gender and genetic variation at the TCF7L2 locus predict the development of metabolic syndrome [Internet]. J Nutr Biochem. 2012 Mar;23(3):239-44. [cited 2018 Dec 15] Available from: http://www.ncbi.nlm.nih.gov/ pubmed/21543200

37 Grimaldi KA, van Ommen B, Ordovas JM, Parnell LD, Mathers JC, Bendik I, et al. Proposed guidelines to evaluate scientific validity and evidence for genotype-based dietary advice [Internet]. Genes Nutr. 2017 Dec;12(1):35. [cited 2019 Mar 28] Available from: http://www.ncbi.nlm.nih.gov/pubmed/29270237

38 Trouwborst I, Bowser SM, Goossens GH, Blaak EE. Ectopic Fat Accumulation in Distinct Insulin Resistant Phenotypes; Targets for Personalized Nutritional Interventions. Front Nutr. 2018 Sep; 5:77.

39 Ordovas JM, Ferguson LR, Tai ES, Mathers JC. Personalised nutrition and health. BMJ. 2018 Jun;361:bmj.k2173.

40 Mulligan AA, Luben RN, Bhaniani A, Parry-Smith DJ, O'Connor L, Khawaja AP, et al.; EPIC-Norfolk FFQ Study. A new tool for converting food frequency questionnaire data into nutrient and food group values: FETA research methods and availability [Internet]. BMJ Open. 2014 Mar;4(3):e004503. [cited 2019 Mar 28] Available from: http://bmjopen.bmj.com/lookup/doi/10.1136/bmjopen-2013-004503

41 Dao MC, Subar AF, Warthon-Medina M, Cade JE, Burrows T, Golley RK, et al. Dietary assessment toolkits: an overview [Internet]. Public Health Nutr. 2019 Mar;22(3):404-18. [cited 2019 May 13] Available from: http:// www.ncbi.nlm.nih.gov/pubmed/30428939

42 van Lee L, Geelen A, van Huysduynen EJ, de Vries JH, van't Veer P, Feskens EJ. The Dutch Healthy Diet index (DHD-index): an instrument to measure adherence to the Dutch Guidelines for a Healthy Diet [Internet]. Nutr J. 2012 Jul;11(1):49. [cited 2019 Mar 28] Available from: http://nutritionj.biomedcentral.com/ articles/10.1186/1475-2891-11-49

43 Onvani S, Haghighatdoost F, Surkan PJ, Larijani B, Azadbakht L. Adherence to the Healthy Eating Index and Alternative Healthy Eating Index dietary patterns and mortality from all causes, cardiovascular disease and cancer: a meta-analysis of observational studies [Internet]. J Hum Nutr Diet. 2017 Apr;30(2):216-26. [cited 2019 Mar 28] Available from: http://www.ncbi.nlm.nih.gov/pubmed/27620213 
Alligier et al.: OBEDIS Core Variables Project

44 Greeno CG, Wing RR. Stress-induced eating [Internet]. Psychol Bull. 1994 May;115(3):444-64. [cited 2018 Dec 17] Available from: http://www.ncbi.nlm.nih.gov/pubmed/8016287

45 Yau YH, Potenza MN. Stress and eating behaviors [Internet]. Minerva Endocrinol. 2013 Sep;38(3):255-67. [cited 2018 Dec 13] Available from: https://www.minervamedica.it/en/journals/minerva-endocrinologica/ article.php?cod=R07Y2013N03A0255

46 Wardle J, Steptoe A, Oliver G, Lipsey Z. Stress, dietary restraint and food intake [Internet]. J Psychosom Res. 2000 Feb; 48(2):195-202. [cited 2018 Dec 17] Available from: https://www.sciencedirect.com/science/ article/pii/S0022399900000763?via\%3Dihub

47 van Strien T. Causes of Emotional Eating and Matched Treatment of Obesity [Internet]. Curr Diab Rep. 2018 Apr;18(6):35. [cited 2018 Dec 12] Available from: http://link.springer.com/10.1007/s11892-018-1000-x

48 Braden A, Flatt SW, Boutelle KN, Strong D, Sherwood NE, Rock CL. Emotional eating is associated with weight loss success among adults enrolled in a weight loss program [Internet]. J Behav Med. 2016 Aug;39(4):727-32. [cited 2018 Nov 26] Available from: http://www.ncbi.nlm.nih.gov/pubmed/26931635

49 van Strien T, Frijters JE, Bergers GP, Defares PB. The Dutch Eating Behavior Questionnaire (DEBQ) for assessment of restrained, emotional, and external eating behavior [Internet]. Int J Eat Disord. 1986 Feb;5(2): 295-315. [cited 2018 Dec 17] Available from: http://doi.wiley.com/10.1002/1098-108X\%28198602\%295 \%3A2\%3C295\%3A\%3AAID-EAT2260050209\%3E3.0.CO\%3B2-T

50 Caspersen CJ, Powell KE, Christenson GM. Physical activity, exercise, and physical fitness: definitions and distinctions for health-related research [Internet]. Public Health Rep. 1985 Mar-Apr;100(2):126-31. [cited 2018 Dec 16] Available from: http://www.ncbi.nlm.nih.gov/pubmed/3920711

51 Lee IM, Djoussé L, Sesso HD, Wang L, Buring JE. Physical activity and weight gain prevention [Internet]. JAMA. 2010 Mar;303(12):1173-9. [cited 2018 Dec 16] Available from: http://www.ncbi.nlm.nih.gov/ pubmed/20332403

52 US Department of Health and Human Services. Physical Activity Guidelines for Americans, 2nd edition [Internet]. 2018 [cited 2019 Jan 13]. Available from: https://health.gov/paguidelines/second-edition/pdf/ Physical_Activity_Guidelines_2nd_edition.pdf

53 Donnelly JE, Blair SN, Jakicic JM, Manore MM, Rankin JW, Smith BK, et al. Appropriate Physical Activity Intervention Strategies for Weight Loss and Prevention of Weight Regain for Adults. Med Sci Sport Exerc. 2009 Feb; 41(2):459-71.

54 Swift DL, Johannsen NM, Lavie CJ, Earnest CP, Church TS. The role of exercise and physical activity in weight loss and maintenance [Internet]. Prog Cardiovasc Dis. 2014 Jan-Feb;56(4):441-7. [cited 2018 Dec 16] Available from: http://www.ncbi.nlm.nih.gov/pubmed/24438736

55 Tremblay MS, LeBlanc AG, Kho ME, Saunders TJ, Larouche R, Colley RC, et al. Systematic review of sedentary behaviour and health indicators in school-aged children and youth [Internet]. Int J Behav Nutr Phys Act. 2011 Sep;8(1):98. [cited 2018 Dec 16] Available from: http://www.ncbi.nlm.nih.gov/pubmed/21936895

56 Lee IM, Shiroma EJ. Using accelerometers to measure physical activity in large-scale epidemiological studies: issues and challenges [Internet]. Br J Sports Med. 2014 Feb;48(3):197-201. [cited 2018 Dec 26] Available from: http://www.ncbi.nlm.nih.gov/pubmed/24297837

57 Paffenbarger RS Jr, Blair SN, Lee IM, Hyde RT. Measurement of physical activity to assess health effects in freeliving populations [Internet]. Med Sci Sports Exerc. 1993 Jan;25(1):60-70. [cited 2018 Dec 29] Available from: http://www.ncbi.nlm.nih.gov/pubmed/8423758

58 McAuley PA, Kokkinos PF, Oliveira RB, Emerson BT, Myers JN. Obesity paradox and cardiorespiratory fitness in 12,417 male veterans aged 40 to 70 years [Internet]. Mayo Clin Proc. 2010 Feb;85(2):115-21. [cited 2018 Dec 27] Available from: https://linkinghub.elsevier.com/retrieve/pii/S0025619611603832

59 Lee CD, Blair SN, Jackson AS. Cardiorespiratory fitness, body composition, and all-cause and cardiovascular disease mortality in men [Internet]. Am J Clin Nutr. 1999 Mar;69(3):373-80. [cited 2018 Dec 29] Available from: http://www.ncbi.nlm.nih.gov/pubmed/10075319

60 Hawkins MN, Raven PB, Snell PG, Stray-Gundersen J, Levine BD. Maximal oxygen uptake as a parametric measure of cardiorespiratory capacity [Internet]. Med Sci Sports Exerc. 2007 Jan;39(1):103-7. [cited 2019 Jan 6] Available from: http://www.ncbi.nlm.nih.gov/pubmed/17218891

61 Guyatt GH, Sullivan MJ, Thompson PJ, Fallen EL, Pugsley SO, Taylor DW, et al. The 6-minute walk: a new measure of exercise capacity in patients with chronic heart failure [Internet]. Can Med Assoc J. 1985 Apr; 132(8):919-23. [cited 2019 Jan 7] Available from: http://www.ncbi.nlm.nih.gov/pubmed/3978515

62 ATS statement: guidelines for the six-minute walk test. Am J Respir Crit Care Med. 2002 Jul;166(1):111-7.

63 Rikli RE, Jones CJ. Senior fitness test manual. Windsor: Human Kinetics; 2001. p. 161.

64 Sykes K, Roberts A. The Chester step test-a simple yet effective tool for the prediction of aerobic capacity [Internet]. Physiotherapy. 2004 Dec;90(4):183-8. [cited 2019 Jan 7] Available from: https://www.sciencedirect.com/science/article/abs/pii/S0031940604000574

65 Roberts HC, Denison HJ, Martin HJ, Patel HP, Syddall H, Cooper C, et al. A review of the measurement of grip strength in clinical and epidemiological studies: towards a standardised approach [Internet]. Age Ageing. 2011 Jul;40(4):423-9. [cited 2019 Mar 26] Available from: http://www.ncbi.nlm.nih.gov/pubmed/21624928

66 Bass J, Takahashi JS. Circadian integration of metabolism and energetics [Internet]. Science. 2010 Dec; 330(6009):1349-54. [cited 2018 Nov 26] Available from: http://www.ncbi.nlm.nih.gov/pubmed/21127246

67 Erren TC, Reiter RJ. Defining chronodisruption [Internet]. J Pineal Res. 2009 Apr;46(3):245-7. [cited 2018 Nov 28] Available from: http://www.ncbi.nlm.nih.gov/pubmed/19215573 
68 Czeisler CA, Johnson MP, Duffy JF, Brown EN, Ronda JM, Kronauer RE. Exposure to bright light and darkness to treat physiologic maladaptation to night work [Internet]. N Engl J Med. 1990 May;322(18):1253-9. [cited 2019 Jan 22] Available from: http://www.nejm.org/doi/abs/10.1056/NEJM199005033221801

69 McHill AW, Wright KP Jr. Role of sleep and circadian disruption on energy expenditure and in metabolic predisposition to human obesity and metabolic disease. Obes Rev. 2017 Feb;18 Suppl 1:15-24.

70 Leger D, Bayon V, de Sanctis A. The role of sleep in the regulation of body weight [Internet]. Mol Cell Endocrinol. 2015 Dec;418(Pt 2):101-7. [cited 2018 Dec 10] Available from: http://www.ncbi.nlm.nih.gov/ pubmed/26123586

71 Sun M, Feng W, Wang F, Li P, Li Z, Li M, et al. Meta-analysis on shift work and risks of specific obesity types [Internet]. Obes Rev. 2018 Jan;19(1):28-40. [cited 2018 Nov 26] Available from: http://www.ncbi.nlm.nih. gov/pubmed/28975706

72 Roenneberg T, Allebrandt KV, Merrow M, Vetter C. Social jetlag and obesity. Curr Biol. 2012 May;22(10):93943.

73 Theorell-Haglöw J, Lindberg E. Sleep Duration and Obesity in Adults: What Are the Connections? [Internet]. Curr Obes Rep. 2016 Sep;5(3):333-43. [cited 2018 Dec 10] Available from: http://www.ncbi.nlm.nih.gov/ pubmed/27372108

74 Capers PL, Fobian AD, Kaiser KA, Borah R, Allison DB. A systematic review and meta-analysis of randomized controlled trials of the impact of sleep duration on adiposity and components of energy balance [Internet]. Obes Rev. 2015 Sep;16(9):771-82. [cited 2018 Dec 10] Available from: http://www.ncbi.nlm.nih.gov/ pubmed/26098388

75 Dempsey JA, Veasey SC, Morgan BJ, O’Donnell CP. Pathophysiology of sleep apnea [Internet]. Physiol Rev. 2010 Jan;90(1):47-112. [cited 2018 Dec 13] Available from: http://www.ncbi.nlm.nih.gov/pubmed/20086074

76 Castaneda A, Jauregui-Maldonado E, Ratnani I, Varon J, Surani S. Correlation between metabolic syndrome and sleep apnea [Internet]. World J Diabetes. 2018 Apr;9(4):66-71. [cited 2018 Nov 28] Available from: http:// www.ncbi.nlm.nih.gov/pubmed/29765510

77 Tachikawa R, Ikeda K, Minami T, Matsumoto T, Hamada S, Murase K, et al. Changes in Energy Metabolism after Continuous Positive Airway Pressure for Obstructive Sleep Apnea [Internet]. Am J Respir Crit Care Med. 2016 Sep;194(6):729-38. [cited 2018 Nov 28] Available from: http://www.ncbi.nlm.nih.gov/pubmed/26930227

78 Martínez-Cerón E, Barquiel B, Bezos AM, Casitas R, Galera R, García-Benito C, et al. Effect of Continuous Positive Airway Pressure on Glycemic Control in Patients with Obstructive Sleep Apnea and Type 2 Diabetes. A Randomized Clinical Trial [Internet]. Am J Respir Crit Care Med. 2016 Aug;194(4):476-85. [cited 2018 Nov 28] Available from: http://www.atsjournals.org/doi/10.1164/rccm.201510-19420C

79 Chung F, Yegneswaran B, Liao P, Chung SA, Vairavanathan S, Islam S, et al. STOP questionnaire: a tool to screen patients for obstructive sleep apnea [Internet]. Anesthesiology. 2008 May;108(5):812-21. [cited 2019 Jan 22] Available from: http://www.ncbi.nlm.nih.gov/pubmed/18431116

80 Chiu HY, Chen PY, Chuang LP, Chen NH, Tu YK, Hsieh YJ, et al. Diagnostic accuracy of the Berlin questionnaire, STOP-BANG, STOP, and Epworth sleepiness scale in detecting obstructive sleep apnea: A bivariate metaanalysis. Sleep Med Rev. 2017 Dec;36:57-70.

81 Bidulescu A, Din-Dzietham R, Coverson DL, Chen Z, Meng YX, Buxbaum SG, et al. Interaction of sleep quality and psychosocial stress on obesity in African Americans: the Cardiovascular Health Epidemiology Study (CHES) [Internet]. BMC Public Health. 2010 Sep;10(1):581. [cited 2018 Dec 13] Available from: http://www. ncbi.nlm.nih.gov/pubmed/20920190

82 Vgontzas AN, Fernandez-Mendoza J, Miksiewicz T, Kritikou I, Shaffer ML, Liao D, et al. Unveiling the longitudinal association between short sleep duration and the incidence of obesity: the Penn State Cohort [Internet]. Int J Obes. 2014 Jun;38(6):825-32. [cited 2018 Dec 10] Available from: http://www.ncbi.nlm.nih.gov/ pubmed/24100421

83 Tenk J, Mátrai P, Hegyi P, Rostás I, Garami A, Szabó I, et al. Perceived stress correlates with visceral obesity and lipid parameters of the metabolic syndrome: A systematic review and meta-analysis. Psychoneuroendocrinology. 2018 Sep; 95:63-73.

84 Vgontzas AN, Lin HM, Papaliaga M, Calhoun S, Vela-Bueno A, Chrousos GP, et al. Short sleep duration and obesity: the role of emotional stress and sleep disturbances [Internet]. Int J Obes. 2008 May;32(5):801-9. [cited 2019 Jan 6] Available from: http://www.ncbi.nlm.nih.gov/pubmed/18253159

85 Cohen S, Kamarck T, Mermelstein R. A global measure of perceived stress [Internet]. J Health Soc Behav. 1983 Dec;24(4):385-96. [cited2018Dec17] Available from: http://www.jstor.org/stable/2136404?origin=crossref

86 World Health Organization. Obesity : preventing and managing the global epidemic : report of a WHO consultation. Geneva: World Health Organization; 2000. p. 253.

87 Afshin A, Forouzanfar MH, Reitsma MB, Sur P, Estep K, Lee A, et al.; GBD 2015 Obesity Collaborators. Health Effects of Overweight and Obesity in 195 Countries over 25 Years [Internet]. N Engl J Med. 2017 Jul;377(1): 13-27. [cited 2018 Nov 23] Available from: http://www.nejm.org/doi/10.1056/NEJMoa1614362

88 Duren DL, Sherwood RJ, Czerwinski SA, Lee M, Choh AC, Siervogel RM, et al. Body composition methods: comparisons and interpretation [Internet]. J Diabetes Sci Technol. 2008 Nov;2(6):1139-46. [cited 2018 Nov 27] Available from: http://www.ncbi.nlm.nih.gov/pubmed/19885303

89 Blundell JE, Dulloo AG, Salvador J, Frühbeck G; EASO SAB Working Group on BMI. Beyond BMI—phenotyping the obesities [Internet]. Obes Facts. 2014;7(5):322-8. [cited 2018 Nov 26] Available from: http://www.ncbi. nlm.nih.gov/pubmed/25485991 
90 Gómez-Ambrosi J, Silva C, Galofré JC, Escalada J, Santos S, Millán D, et al. Body mass index classification misses subjects with increased cardiometabolic risk factors related to elevated adiposity [Internet]. Int J Obes. 2012 Feb;36(2):286-94. [cited 2018 Nov 27] Available from: http://www.ncbi.nlm.nih.gov/pubmed/21587201

91 Gómez-Ambrosi J, Silva C, Galofré JC, Escalada J, Santos S, Gil MJ, et al. Body adiposity and type 2 diabetes: increased risk with a high body fat percentage even having a normal BMI [Internet]. Obesity (Silver Spring). 2011 Jul;19(7):1439-44. [cited 2018 Nov 26] Available from: http://www.ncbi.nlm.nih.gov/pubmed/ 21394093

92 Frühbeck G, Toplak H, Woodward E, Yumuk V, Maislos M, Oppert JM; Executive Committee of the European Association for the Study of Obesity. Obesity: the gateway to ill health - an EASO position statement on a rising public health, clinical and scientific challenge in Europe [Internet]. Obes Facts. 2013;6(2):117-20. [cited 2018 Dec 8] Available from: http://www.ncbi.nlm.nih.gov/pubmed/23548858

93 Ashwell M, Gibson S. A proposal for a primary screening tool: 'Keep your waist circumference to less than half your height' [Internet]. BMC Med. 2014 Nov;12(1):207. [cited 2018 Dec 8] Available from: http://www.ncbi. nlm.nih.gov/pubmed/25377944

94 Ashwell M, Gibson S. Waist-to-height ratio as an indicator of 'early health risk': simpler and more predictive than using a 'matrix' based on BMI and waist circumference [Internet]. BMJ Open. 2016 Mar;6(3):e010159. [cited 2018 Dec 8] Available from: http://www.ncbi.nlm.nih.gov/pubmed/26975935

95 Rasaei N, Mirzababaei A, Arghavani H, Tajik S, Keshavarz SA, Yekaninejad MS, et al. A comparison of the sensitivity and specificity of anthropometric measurements to predict unhealthy metabolic phenotype in overweight and obese women [Internet]. Diabetes Metab Syndr. 2018 Nov;12(6):1147-53. [cited 2018 Dec 8] Available from: http://www.ncbi.nlm.nih.gov/pubmed/30017504

96 Tchernof A, Després JP. Pathophysiology of human visceral obesity: an update [Internet]. Physiol Rev. 2013 Jan;93(1):359-404. [cited 2018 Dec 8] Available from: http://www.ncbi.nlm.nih.gov/pubmed/23303913

97 Khalili S, Hatami M, Hadaegh F, Sheikholeslami F, Azizi F. Prediction of cardiovascular events with consideration of general and central obesity measures in diabetic adults: results of the 8.4-year follow-up [Internet]. Metab Syndr Relat Disord. 2012 Jun;10(3):218-24. [cited 2018 Dec 9] Available from: http://www.ncbi.nlm. nih.gov/pubmed/22324792

98 Czernichow S, Kengne AP, Huxley RR, Batty GD, de Galan B, Grobbee D, et al.; ADVANCE Collaborative Group. Comparison of waist-to-hip ratio and other obesity indices as predictors of cardiovascular disease risk in people with type-2 diabetes: a prospective cohort study from ADVANCE [Internet]. Eur J Cardiovasc Prev Rehabil. 2011 Apr;18(2):312-9. [cited 2018 Dec 9] Available from: http://www.ncbi.nlm.nih.gov/ pubmed/20628304

99 Cepeda-Valery B, Pressman GS, Figueredo VM, Romero-Corral A. Impact of obesity on total and cardiovascular mortality-fat or fiction? [Internet]. Nat Rev Cardiol. 2011 Apr;8(4):233-7. [cited 2019 Jan 22] Available from: http://www.ncbi.nlm.nih.gov/pubmed/21263454

100 Ben-Noun L, Sohar E, Laor A. Neck circumference as a simple screening measure for identifying overweight and obese patients [Internet]. Obes Res. 2001 Aug;9(8):470-7. [cited 2018 Nov 26] Available from: http:// www.ncbi.nlm.nih.gov/pubmed/11500527

101 Kroll C, Mastroeni SS, Czarnobay SA, Ekwaru JP, Veugelers PJ, Mastroeni MF. The accuracy of neck circumference for assessing overweight and obesity: a systematic review and meta-analysis [Internet]. Ann Hum Biol. 2017 Dec;44(8):667-77. [cited 2018Dec 8] Available from: http://www.ncbi.nlm.nih.gov/pubmed/29037078

102 Kawaguchi Y, Fukumoto S, Inaba M, Koyama H, Shoji T, Shoji S, et al. Different impacts of neck circumference and visceral obesity on the severity of obstructive sleep apnea syndrome [Internet]. Obesity (Silver Spring). 2011Feb;19(2):276-82.[cited2018Nov26]Availablefrom:http://www.ncbi.nlm.nih.gov/pubmed/20706203

103 Onat A, Hergenç G, Yüksel H, Can G, Ayhan E, Kaya Z, et al. Neck circumference as a measure of central obesity: associations with metabolic syndrome and obstructive sleep apnea syndrome beyond waist circumference [Internet]. Clin Nutr. 2009 Feb;28(1):46-51. [cited 2018 Nov 26] Available from: http://www.ncbi.nlm.nih. gov/pubmed/19010573

104 Huang B, Zhu M, Wu T, Zhou J, Liu Y, Chen X, et al. Neck Circumference, along with Other Anthropometric Indices, Has an Independent and Additional Contribution in Predicting Fatty Liver Disease. PLoS One. 2015 Feb;10(2):e0118071.

105 Shuster A, Patlas M, Pinthus JH, Mourtzakis M. The clinical importance of visceral adiposity: a critical review of methods for visceral adipose tissue analysis [Internet]. Br J Radiol. 2012 Jan;85(1009):1-10. [cited 2018 Dec 8] Available from: http://www.ncbi.nlm.nih.gov/pubmed/21937614

106 Rosenbaum M, Agurs-Collins T, Bray MS, Hall KD, Hopkins M, Laughlin M, et al. Accumulating Data to Optimally Predict Obesity Treatment (ADOPT): Recommendations from the Biological Domain. Obesity (Silver Spring). 2018 Apr;26 Suppl 2:S25-34.

107 Müller MJ, Enderle J, Bosy-Westphal A. Changes in Energy Expenditure with Weight Gain and Weight Loss in Humans [Internet]. Curr Obes Rep. 2016 Dec;5(4):413-23. [cited 2018 Dec 8] Available from: http://www. ncbi.nlm.nih.gov/pubmed/27739007

108 Clapham JC. Treating obesity: pharmacology of energy expenditure [Internet]. Curr Drug Targets. 2004 Apr; 5(3):309-23. [cited 2018 Dec 9] Available from: http://www.ncbi.nlm.nih.gov/pubmed/15058315

109 Johansson G, Westerterp KR. Assessment of the physical activity level with two questions: validation with doubly labeled water [Internet]. Int J Obes. 2008 Jun;32(6):1031-3. [cited 2019 Jan 22] Available from: http:// www.ncbi.nlm.nih.gov/pubmed/18392036 
110 Knudsen N, Laurberg P, Rasmussen LB, Bülow I, Perrild H, Ovesen L, et al. Small differences in thyroid function may be important for body mass index and the occurrence of obesity in the population [Internet]. J Clin Endocrinol Metab. 2005 Jul;90(7):4019-24. [cited 2019 Mar 26] Available from: http://www.ncbi.nlm.nih.gov/ pubmed/15870128

111 Slopien R, Wender-Ozegowska E, Rogowicz-Frontczak A, Meczekalski B, Zozulinska-Ziolkiewicz D, Jaremek JD, et al. Menopause and diabetes: EMAS clinical guide. Maturitas. 2018 Nov;117:6-10.

112 Wierman ME, Auchus RJ, Haisenleder DJ, Hall JE, Handelsman D, Hankinson S, et al. Editorial: the new instructions to authors for the reporting of steroid hormone measurements [Internet]. J Clin Endocrinol Metab. 2014 Dec;99(12):4375-4375. [cited2019Mar26] Availablefrom:http://www.ncbi.nlm.nih.gov/pubmed/25354278

113 Davies MJ, D'Alessio DA, Fradkin J, Kernan WN, Mathieu C, Mingrone G, et al. Management of Hyperglycemia in Type 2 Diabetes, 2018. A Consensus Report by the American Diabetes Association (ADA) and the European Association for the Study of Diabetes (EASD) [Internet]. Diabetes Care. 2018 Dec;41(12):2669-701. [cited 2019 Jan 13] Available from: http://www.ncbi.nlm.nih.gov/pubmed/30291106

114 Bradshaw PT, Monda KL, Stevens J. Metabolic syndrome in healthy obese, overweight, and normal weight individuals: the Atherosclerosis Risk in Communities Study [Internet]. Obesity (Silver Spring). 2013 Jan; 21(1):203-9. [cited 2019 Mar 26] Available from: http://www.ncbi.nlm.nih.gov/pubmed/23505187

115 Wilding JP. The importance of weight management in type 2 diabetes mellitus [Internet]. Int J Clin Pract. 2014 Jun;68(6):682-91. [cited 2019 Jan 13] Available from: http://www.ncbi.nlm.nih.gov/pubmed/24548654

116 Wallace TM, Levy JC, Matthews DR. Use and abuse of HOMA modeling [Internet]. Diabetes Care. 2004 Jun; 27(6):1487-95. [cited 2019 Jun 4] Available from: http://www.ncbi.nlm.nih.gov/pubmed/15161807

117 Wei M, Kampert JB, Barlow CE, Nichaman MZ, Gibbons LW, Paffenbarger RS Jr, et al. Relationship between low cardiorespiratory fitness and mortality in normal-weight, overweight, and obese men [Internet]. JAMA. 1999 Oct;282(16):1547-53. [cited 2018 Dec 27] Available from: http://www.ncbi.nlm.nih.gov/pubmed/10546694

118 Emberson JR, Whincup PH, Morris RW, Walker M. Re-assessing the contribution of serum total cholesterol, blood pressure and cigarette smoking to the aetiology of coronary heart disease: impact of regression dilution bias [Internet]. Eur Heart J. 2003 Oct;24(19):1719-26. [cited 2019 Jan 13] Available from: http://www.ncbi. nlm.nih.gov/pubmed/14522566

119 Anderson KM, Odell PM, Wilson PW, Kannel WB. Cardiovascular disease risk profiles [Internet]. Am Heart J. 1991 Jan;121(1 Pt 2):293-8. [cited 2019 Jan 13] Available from: http://www.ncbi.nlm.nih.gov/ pubmed/1985385

120 Sheridan S, Pignone M, Mulrow C. Framingham-based tools to calculate the global risk of coronary heart disease: a systematic review of tools for clinicians [Internet]. J Gen Intern Med. 2003 Dec;18(12):1039-52. [cited 2019 Jan 13] Available from: http://www.ncbi.nlm.nih.gov/pubmed/14687264

121 Collins GS, Altman DG. An independent external validation and evaluation of QRISK cardiovascular risk prediction: a prospective open cohort study. BMJ. 2009 Jul;339:b2584.

122 Wierzbicki AS. Lumping and splitting in cardiovascular risk [Internet]. Int J Clin Pract. 2012 Jun;66(6):522-4. [cited 2019 Jan 13] Available from: http://doi.wiley.com/10.1111/j.1742-1241.2012.02949.x

123 Helfand M, Buckley DI, Freeman M, Fu R, Rogers K, Fleming C, et al. Emerging risk factors for coronary heart disease: a summary of systematic reviews conducted for the U.S. Preventive Services Task Force [Internet]. Ann Intern Med. 2009 Oct;151(7):496-507. [cited 2019 Jan 13] Available from: http://www.ncbi.nlm.nih. gov/pubmed/19805772

124 Danesh J, Wheeler JG, Hirschfield GM, Eda S, Eiriksdottir G, Rumley A, et al. C-reactive protein and other circulating markers of inflammation in the prediction of coronary heart disease [Internet]. N Engl J Med. 2004 Apr; 350(14):1387-97. [cited 2019 Jan 13] Available from: http://www.ncbi.nlm.nih.gov/pubmed/15070788

125 Emerging Risk Factors Collaboration; Kaptoge S, Di Angelantonio E, Lowe G, Pepys MB, Thompson SG, et al. C-reactive protein concentration and risk of coronary heart disease, stroke, and mortality: an individual participant meta-analysis. Lancet. 2010 Jan 9;375(9709):132-40.

126 Myers GL, Christenson RH, Cushman M, Ballantyne CM, Cooper GR, Pfeiffer CM, et al.; NACB LMPG Committee Members. National Academy of Clinical Biochemistry Laboratory Medicine Practice guidelines: emerging biomarkers for primary prevention of cardiovascular disease [Internet]. Clin Chem. 2009 Feb;55(2):378-84. [cited 2019 Jan 13] Available from: http://www.ncbi.nlm.nih.gov/pubmed/19106185

127 Ridker PM, Cook N. Clinical usefulness of very high and very low levels of C-reactive protein across the full range of Framingham Risk Scores [Internet]. Circulation. 2004 Apr;109(16):1955-9. [cited 2019 Jan 13] Available from: http://www.ncbi.nlm.nih.gov/pubmed/15051634

128 Matthews DR, Hosker JP, Rudenski AS, Naylor BA, Treacher DF, Turner RC. Homeostasis model assessment: insulin resistance and beta-cell function from fasting plasma glucose and insulin concentrations in man [Internet]. Diabetologia. 1985 Jul;28(7):412-9. [cited 2019 Jan 13] Available from: http://www.ncbi.nlm.nih. gov/pubmed/3899825

129 Kong LC, Tap J, Aron-Wisnewsky J, Pelloux V, Basdevant A, Bouillot JL, et al. Gut microbiota after gastric bypass in human obesity: increased richness and associations of bacterial genera with adipose tissue genes [Internet]. Am J Clin Nutr. 2013 Jul;98(1):16-24. [cited 2019 Jan 13] Available from: http://www.ncbi.nlm.nih.gov/ pubmed/23719559

130 Fortmann SP, Haskell WL, Wood PD. Effects of weight loss on clinic and ambulatory blood pressure in normotensive men [Internet]. Am J Cardiol. 1988 Jul;62(1):89-93. [cited 2019 Jan 14] Available from: http://www. ncbi.nlm.nih.gov/pubmed/3381757 
Alligier et al.: OBEDIS Core Variables Project

131 Capodaglio P, De Souza SA, Parisio C, Precilios H, Vismara L, Cimolin V, et al. Reference values for the 6-Min Walking Test in obese subjects [Internet]. Disabil Rehabil. 2013 Jul;35(14):1199-203. [cited 2019 Jan 13] Available from: http://www.ncbi.nlm.nih.gov/pubmed/23061440

132 Beriault K, Carpentier AC, Gagnon C, Ménard J, Baillargeon JP, Ardilouze JL, et al. Reproducibility of the 6-minute walk test in obese adults [Internet]. Int J Sports Med. 2009 Oct;30(10):725-7. [cited 2019 Jan 13] Available from: http://www.ncbi.nlm.nih.gov/pubmed/19585400

133 Rasekaba T, Lee AL, Naughton MT, Williams TJ, Holland AE. The six-minute walk test: a useful metric for the cardiopulmonary patient [Internet]. Intern Med J. 2009 Aug;39(8):495-501. [cited 2019 Jan 13] Available from: http://www.ncbi.nlm.nih.gov/pubmed/19732197

134 Panosian J, Ding SA, Wewalka M, Simonson DC, Goebel-Fabbri A, Foster K, et al. Physical Activity in Obese Type 2 Diabetes After Gastric Bypass or Medical Management [Internet]. Am J Med. 2017 Jan;130(1):83-92. [cited 2019 Jan 13] Available from: http://www.ncbi.nlm.nih.gov/pubmed/27555097

135 Goran M, Fields DA, Hunter GR, Herd SL, Weinsier RL. Total body fat does not influence maximal aerobic capacity [Internet]. Int J Obes Relat Metab Disord. 2000 Jul;24(7):841-8. [cited 2019 Jan 14] Available from: http://www.ncbi.nlm.nih.gov/pubmed/10918530

136 Hothi SS, Tan DK, Partridge G, Tan LB. Is low VO2max/kg in obese heart failure patients indicative of cardiac dysfunction? Int J Cardiol. 2015 Apr;184:755-62.

137 Nicklas BJ, Wang X, You T, Lyles MF, Demons J, Easter L, et al. Effect of exercise intensity on abdominal fat loss during calorie restriction in overweight and obese postmenopausal women: a randomized, controlled trial [Internet]. Am J Clin Nutr. 2009 Apr;89(4):1043-52. [cited 2019 Jan 14] Available from: http://www.ncbi.nlm. nih.gov/pubmed/19211823

138 Omran J, Firwana B, Koerber S, Bostick B, Alpert MA. Effect of obesity and weight loss on ventricular repolarization: a systematic review and meta-analysis [Internet]. Obes Rev. 2016 Jun;17(6):520-30. [cited 2019 Jan 14] Available from: http://www.ncbi.nlm.nih.gov/pubmed/26956255

139 Okin PM, Devereux RB, Howard BV, Fabsitz RR, Lee ET, Welty TK. Assessment of QT interval and QT dispersion for prediction of all-cause and cardiovascular mortality in American Indians: The Strong Heart Study [Internet]. Circulation. 2000 Jan;101(1):61-6. [cited 2019 Jan 14] Available from: http://www.ncbi.nlm.nih.gov/ pubmed/10618305

140 Jonas DE, Amick HR, Feltner C, Weber RP, Arvanitis M, Stine A, et al. Screening for Obstructive Sleep Apnea in Adults. Screening for Obstructive Sleep Apnea in Adults: An Evidence Review for the U.S. Preventive Services Task Force. Rockville: Agency for Healthcare Research and Quality (US); 2017 Jan. Available from: http:// www.ncbi.nlm.nih.gov/pubmed/28211654

141 Marchesini G, Moscatiello S, Di Domizio S, Forlani G. Obesity-Associated Liver Disease. J Clin Endocrinol Metab. 2008 Nov;93(11 Suppl 1):S74-80.

142 Association for the Study of the Liver EASL, European Association for the Study of Diabetes (EASD), European Association for the Study of Obesity (EASO). EASL-EASD-EASO Clinical Practice Guidelines for the management of non-alcoholic fatty liver disease. J Hepatol. 2016 Jun;64(6):1388-402.

143 Chalasani N, Younossi Z, Lavine JE, Charlton M, Cusi K, Rinella M, et al. The Diagnosis and Management of Nonalcoholic Fatty Liver Disease: Practice Guidance From the American Association for the Study of Liver Diseases. Hepatology. 2018 Jan;67(1):328-357.

144 National Institute on Drug Abuse. Alcohol Use Disorders Identification Test (AUDIT) [Internet]. 2001 [cited 2019 Jun 23]. Available from: http://www.drugabuse.gov/nidamed-medical-health-professionals

145 King LK, March L, Anandacoomarasamy A. Obesity \& osteoarthritis [Internet]. Indian J Med Res. 2013;138(2): 185-93. [cited 2018 Dec 30] Available from: http://www.ncbi.nlm.nih.gov/pubmed/24056594

146 Warkentin LM, Das D, Majumdar SR, Johnson JA, Padwal RS. The effect of weight loss on health-related quality of life: systematic review and meta-analysis of randomized trials [Internet]. Obes Rev. 2014 Mar; 15(3): 169-82. [cited 2019 Feb 10] Available from: http://www.ncbi.nlm.nih.gov/pubmed/24118750

147 Kersten P, White PJ, Tennant A. The visual analogue WOMAC 3.0 scale-internal validity and responsiveness of the VAS version [Internet]. BMC Musculoskelet Disord. 2010 Apr;11(1):80. [cited 2018 Dec 30] Available from: http://www.ncbi.nlm.nih.gov/pubmed/20433732

148 Basen-Engquist K, Chang M. Obesity and cancer risk: recent review and evidence [Internet]. Curr Oncol Rep. 2011 Feb;13(1):71-6. [cited 2018 Dec 30] Available from: http://www.ncbi.nlm.nih.gov/pubmed/21080117

149 Kim MJ, Maachi M, Debard C, Loizon E, ClémentK, Bruckert E, et al. Increased adiponectin receptor-1 expression in adipose tissue of impaired glucose-tolerant obese subjects during weight loss [Internet]. Eur J Endocrinol. 2006 Jul;155(1):161-5. [cited 2019 Jan 11] Available from: http://www.ncbi.nlm.nih.gov/pubmed/16793963

150 Ravussin E, Gautier JF. Metabolic predictors of weight gain [Internet]. Int J Obes Relat Metab Disord. 1999 Feb; 23(S1 Suppl 1):37-41. [cited 2019 Jan 20] Available from: http://www.nature.com/articles/0800793

151 Kootte RS, Levin E, Salojärvi J, Smits LP, Hartstra AV, Udayappan SD, et al. Improvement of Insulin Sensitivity after Lean Donor Feces in Metabolic Syndrome Is Driven by Baseline Intestinal Microbiota Composition [Internet]. Cell Metab. 2017 Oct;26(4):611-619.e6. [cited 2019 Jan 20] Available from: http://www.ncbi.nlm. nih.gov/pubmed/28978426 
Alligier et al.: OBEDIS Core Variables Project

152 Silventoinen K, Jelenkovic A, Sund R, Hur YM, Yokoyama Y, Honda C, et al. Genetic and environmental effects on body mass index from infancy to the onset of adulthood: an individual-based pooled analysis of 45 twin cohorts participating in the Collaborative project of Development of Anthropometrical measures in Twins (CODATwins) study [Internet]. Am J Clin Nutr. 2016 Aug;104(2):371-9. [cited 2019 Jun 4] Available from: http://www.ncbi.nlm.nih.gov/pubmed/27413137

153 Khera AV, Chaffin M, Wade KH, Zahid S, Brancale J, Xia R, et al. Polygenic Prediction of Weight and Obesity Trajectories from Birth to Adulthood [Internet]. Cell. 2019 Apr;177(3):587-596.e9. [cited 2019 Jun 4] Available from: http://www.ncbi.nlm.nih.gov/pubmed/31002795

154 Bouchard C, Tremblay A, Després JP, Nadeau A, Lupien PJ, Thériault G, et al. The response to long-term overfeeding in identical twins [Internet]. N Engl J Med. 1990 May;322(21):1477-82. [cited 2018 Dec 27] Available from: http://www.nejm.org/doi/abs/10.1056/NEJM199005243222101

$155 \mathrm{Wu} \mathrm{H}$, Wylie-Rosett J, Qi Q. Dietary Interventions for Weight Loss and Maintenance: Preference or Genetic Personalization? [Internet]. Curr Nutr Rep. 2013 Dec;2(4):189-98. [cited 2019 Jan 8] Available from: http:// link.springer.com/10.1007/s13668-013-0061-3

156 Hatoum IJ, Greenawalt DM, Cotsapas C, Reitman ML, Daly MJ, Kaplan LM. Heritability of the weight loss response to gastric bypass surgery [Internet]. J Clin Endocrinol Metab. 2011 Oct;96(10):E1630-3. [cited 2018 Dec 27] Available from: https://academic.oup.com/jcem/article-lookup/doi/10.1210/jc.2011-1130

157 Hasin Y, Seldin M, Lusis A. Multi-omics approaches to disease [Internet]. Genome Biol. 2017 May;18(1):83. [cited 2017 Oct 13] Available from: http://www.ncbi.nlm.nih.gov/pubmed/28476144

158 Ng SF, Lin RC, Laybutt DR, Barres R, Owens JA, Morris MJ. Chronic high-fat diet in fathers programs $\beta$-cell dysfunction in female rat offspring [Internet]. Nature. 2010 Oct;467(7318):963-6. [cited 2019 Jan 18] Available from: http://www.ncbi.nlm.nih.gov/pubmed/20962845

159 de Castro Barbosa T, Ingerslev LR, Alm PS, Versteyhe S, Massart J, Rasmussen M, et al. High-fat diet reprograms the epigenome of rat spermatozoa and transgenerationally affects metabolism of the offspring [Internet]. Mol Metab. 2015 Dec;5(3):184-97. [cited 2019 Jan 18] Available from: http://www.ncbi.nlm.nih.gov/ pubmed/26977389

160 Barres R, Kirchner H, Rasmussen M, Yan J, Kantor FR, Krook A, et al. Weight loss after gastric bypass surgery in human obesity remodels promoter methylation [Internet]. Cell Rep. 2013 Apr;3(4):1020-7. [cited 2019 Jan 18] Available from: http://www.ncbi.nlm.nih.gov/pubmed/23583180 